\title{
Up-regulation of SIRT1 induced by 17beta-estradiol promotes autophagy and inhibits apoptosis in osteoblasts
}

\author{
Yu Wang ${ }^{1,{ }^{*}}$, Runhong Mei ${ }^{1,2,{ }^{*}}$, Shimin $\mathrm{Hao}^{1}$, Peng Luo ${ }^{1}$, Penghao Wang ${ }^{1}$, Yaser Almatari ${ }^{1}$, \\ Lei Guo ${ }^{1}$, Lan Guo ${ }^{1}$ \\ ${ }^{1}$ Department of Orthopedics, The First Hospital of China Medical University, Shenyang 110001, Liaoning, China \\ ${ }^{2}$ Department of Orthopaedics, The Fourth Affiliated Hospital, Medical College, Nanchang University, Nanchang \\ 330006, Jiangxi, China \\ *Equal contribution
}

Correspondence to: Lei Guo, Lan Guo; email: guolei@cmu.edu.cn, guolan@cmu.edu.cn

Keywords: SIRT1, autophagy, apoptosis, AMPK-mTOR, FOXO3a

Received: January 27, $2021 \quad$ Accepted: September 11, $2021 \quad$ Published: October 28, 2021

Copyright: (C) 2021 Wang et al. This is an open access article distributed under the terms of the Creative Commons Attribution License (CC BY 3.0), which permits unrestricted use, distribution, and reproduction in any medium, provided the original author and source are credited.

\section{ABSTRACT}

Osteoporosis is a common systemic skeletal metabolism disorder resulting in bone fragility and increased fracture risk. Silent information regulator factor 2 homolog 1 (SIRT1) is crucial in the regulation of several biological processes, including bone metabolism, autophagy, apoptosis, and aging. This study aimed to assess whether the up-regulation of SIRT1 induced by 17 beta-estradiol (17 $\beta-E 2)$ could promote autophagy and inhibit apoptosis in osteoblasts via the AMPK-mTOR and FOXO3a pathways, respectively. The study found that 17 $\beta$-E2 $\left(10^{-6} \mathrm{M}\right)$ administration induced the up-regulation of SIRT1 in osteoblasts. Up-regulation of SIRT1 induced by $17 \beta-E 2$ increased the expression level of LC3, Beclin-1, Bcl-2, p-AMPK, FOXO3a but decreased caspase-3 and pmTOR expression, and then promoted autophagy and inhibited apoptosis. More autophagosomes were observed under a transmission electron microscope (TEM) in 17 $\beta$-E2 and SRT1720 (a selective SIRT1 activator) co-treated group. When Ex527 (a SIRT1-specific inhibitor) was pretreated, the reversed changes were observed. Taken together, our findings demonstrated that the up-regulation of SIRT1 induced by 17 $\beta$-E2 could promote autophagy via the AMPK-mTOR pathway and inhibit apoptosis via the FOXO3a activation in osteoblasts, and SIRT1 might become a more significant target in osteoporosis treatment.

\section{INTRODUCTION}

Osteoporosis is a systemic bone disease, which is characterized by decreased bone mass and deterioration of bone microstructure, resulting in increased bone fragility and enhanced the risk of fracture [1]. More than 200 million people suffer from osteoporosis, and the incidence rate of osteoporosis is increasing with the prolongation of life span [2]. Over $70 \%$ of those over age 80 are affected. Epidemiology studies have shown that osteoporosis is more common in females than in males [3-5]. In the developed world, $9 \%$ to $38 \%$ of females and $2 \%$ to $8 \%$ of males are affected [6]. The incidence and severity of postmenopausal osteoporosis are associated with the aging process in conjunction with decreasing sex hormones, especially 17beta-estradiol (hereafter 17 $\beta$-E2) [6, 7]. Estrogen/17 $\beta$-E2 replacement has been proved to promote the differentiation of preosteoblasts into osteoblasts and prolong the life span of osteoblasts by curbing apoptosis $[8,9]$, suggesting $17 \beta-$ E2 has a beneficial effect against osteoporosis. As is known to all, $17 \beta$-E2 binds to the specific nuclear estrogen-related receptors (ERRs) ERalpha and ERbeta to exert their physiological functions on cells $[10,11]$. Both ERalpha and ERbeta are expressed in bone tissue $[12,13]$ and bind to $17 \beta-E 2$ to regulate a multitude of 
physiological processes [10]. However, ERalpha is indeed the central factor in the osteoprotective effect of 17ß-E2 [14]. It is reported that ERalpha plays a significant role in the bone response to estrogen in both men and women, while ERbeta only exerts a small protective role in women, but not in men $[14,15]$. Dupont et al. found that deficiency of ERalpha was associated with decreased bone turnover and increased trabecular bone volume in male and female mice [16].

SIRT1, a class III histone deacetylase, participates in life span extension and age-related cellular mechanisms, including autophagy, apoptosis, energy metabolism and anti-aging [17-21]. Previous studies have shown that SIRT1 can reduce bone loss and promote bone formation in mice, indicating that it exerts a protective role in osteoporosis [22, 23]. In vivo and in vitro, experiments previously showed that SIRT1 promotes resveratrol-treated osteoblasts autophagy to protect against osteoporosis via activating the PI3K-Akt-mTOR signaling pathway [24]. Yao et al. have reported that overexpression of SIRT1 protects against osteoporosis by inhibiting apoptosis of osteoblast through the FOXO1 and $\beta$-catenin signaling pathway [25]. These studies have suggested that SIRT1 exerts a crucial protective role in osteoblasts and protects against osteoporosis.

Autophagy is an important mechanism of cellular homeostasis, and compromised autophagy has been proved to be related to the development of osteoporosis [26]. Several studies have suggested that osteoblasts show decreased autophagy in osteoporosis, leading to rapid cell apoptosis and bone mass loss [27-30]. Previous study suggested that AMP-activated protein kinase (AMPK) protects osteogenesis from ovariectomyinduced osteoporosis through autophagy [31]. In addition, AMPK has been proved to promote autophagy by inhibiting the mammalian target of rapamycin (mTOR) signaling pathway [32]. mTOR has been regarded as a potent inhibitor of autophagy. Whether $17 \beta-E 2$ can upregulate SIRT1 expression and then promote osteoblasts autophagy through AMPK-mTOR signaling pathway has not been fully studied.

Previous study demonstrated that overexpression of SIRT1 protects the cardiomyocytes from oxidative stress via forkhead box $\mathrm{O}$ (FOXO) dependent mechanisms [33]. FOXO3a, an important member of the FOXO transcription factor family, has a definite anti-apoptotic and anti-oxidant stress effect [34]. SIRT1 inhibits apoptosis and resists oxidative stress via regulating FOXO3a [35]. Sun et al. reported that overexpression of SIRT1 in mesenchymal stem cells inhibits apoptosis and protects against bone loss in mice via FOXO3a deacetylation [36]. Therefore, we can hypothesize that $17 \beta-E 2$ may induce up-regulation of SIRT1 and then inhibit osteoblasts apoptosis, which may be associated with FOXO3a activation.

In the present study, we sought to understand whether the up-regulation of SIRT1 induced by $17 \beta-\mathrm{E} 2$ could promote autophagy via the AMPK-mTOR signaling pathway and inhibit apoptosis via the FOXO3a activation in osteoblasts, and SIRT1 might become a more significant target in osteoporosis treatment. To evaluate the effect of SIRT1 in autophagy and apoptosis, osteoblasts were pretreated with or without SIRT1activator and inhibitor, and then the changes of autophagy- and apoptosis-related proteins were detected. Furthermore, the target molecules involved in modulating autophagy and apoptosis, such as AMPKmTOR and FOXO3a, were also investigated.

\section{RESULTS}

\section{Up-regulation of SIRT1 expression in hFOB1.19 osteoblasts induced by 17ק-E2}

The hFOB1.19 cells have high homology with human osteoblasts, which is a good model system for studying the biological characteristics of normal osteoblasts in vitro [37]. To investigate whether up-regulation of SIRT1 in hFOB1.19 osteoblasts were induced by $17 \beta$ $\mathrm{E} 2$, cells were cultured with different dosages $17 \beta$-E2 $\left(0,10^{-8}, 10^{-7}\right.$ and $\left.10^{-6} \mathrm{M}\right)$ for $24 \mathrm{~h}$. The expression of SIRT1 mRNA and protein were measured by Western blot (Figure 1A) and RT-PCR (Figure 1B). The results suggested that the expression of SIRT1 was upregulated remarkable after cells incubation with $17 \beta$-E2 $\left(10^{-6} \mathrm{M}\right)$ compared with the control group.

\section{7ß-E2 promoted autophagy in hFOB1.19 osteoblasts}

To investigate the effect of $17 \beta-\mathrm{E} 2$ on autophagy of hFOB1.19 osteoblasts, cells were cultured with different dosages of $17 \beta$-E2 $\left(0,10^{-8}, 10^{-7}\right.$ and $\left.10^{-6} \mathrm{M}\right)$ for 24 hours, and then the expression of autophagy marker microtubule-associated protein 1 light chain 3 (LC3) was measured by Western blot. The results revealed that the expression of LC3 in osteoblasts cultured with $10^{-6}$ M 17ß-E2 was significantly increased than that in the control group (Figure 2A). Osteoblasts were treated with $10^{-6} \mathrm{M} 17 \beta$-E2 for different time $(0,2,4,24,32 \mathrm{~h})$. Similarly, when cells were cultured with $10^{-6} \mathrm{M} 17 \beta-\mathrm{E} 2$ for $24 \mathrm{~h}$, the expression of LC3 was significantly increased compared with the control group (Figure 2B). Furthermore, osteoblasts were pretreated with or without 3-MA (an autophagy inhibitor) prior to incubation with $17 \beta-\mathrm{E} 2\left(10^{-8}\right.$ and $\left.10^{-6} \mathrm{M}\right)$ for $24 \mathrm{~h}$. It is reported that monodansylcadaverine (MDC) staining was considered to be a tracer of autophagosomes to detect autophagy [38, 39]. The change in the intensity 
A
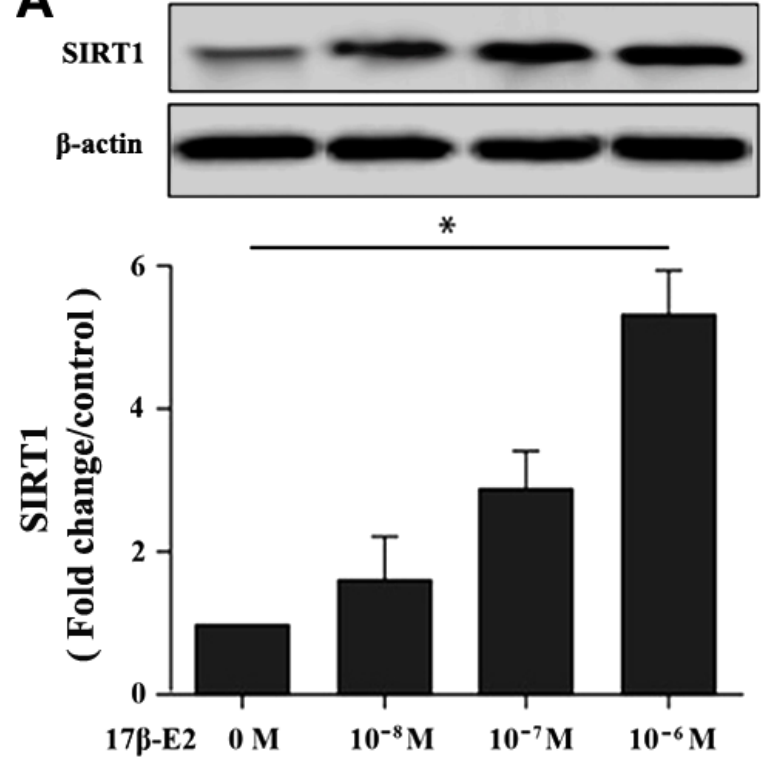

B

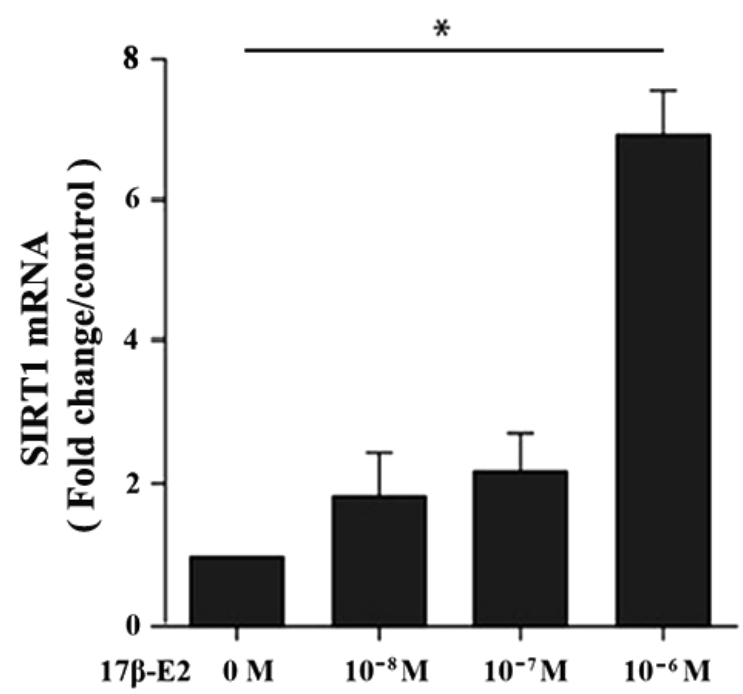

Figure 1. Effect of 17 $\beta$-E2 on the expression level of SIRT1 in hFOB1.19 osteoblasts. (A) Western blotting showed the expression level of SIRT1 in osteoblasts treated with $17 \beta-\mathrm{E} 2\left(0,10^{-8}, 10^{-7}, 10^{-6} \mathrm{M}\right)$ for $24 \mathrm{~h}$. Histogram showed the relative expression of SIRT1 normalized to $\beta$-actin protein, and the densitometry analysis of the blots were estimated by using Image J Software. (B) The expression of SIRT1 mRNA in osteoblasts treated with $17 \beta-E 2\left(0,10^{-8}, 10^{-7}, 10^{-6} \mathrm{M}\right)$ for $24 \mathrm{~h}$, and was assessed using RT-PCR. The data were normalized to GAPDH. Results were expressed as the means \pm SD from 3 independent experiments. Statistically significance was evaluated using the Student's t-test. $* P<0.05$ vs. the control group was considered significant.

A

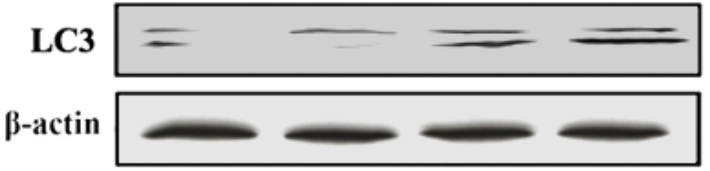

*

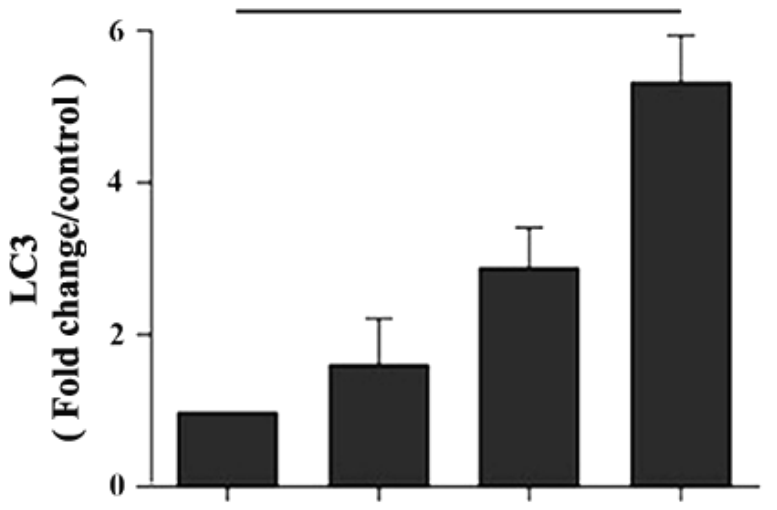

$\begin{array}{lllll}\text { 17ß-E2 } & 0 \mathrm{M} & 10^{-8} \mathrm{M} & 10^{-7} \mathrm{M} & 10^{-6} \mathrm{M}\end{array}$
B
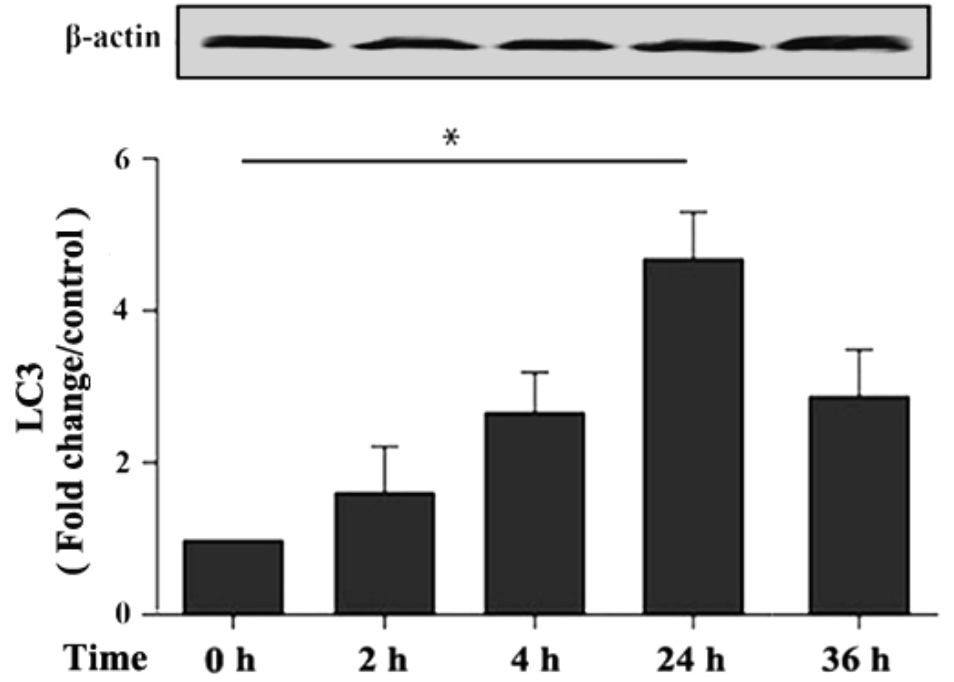

Figure 2. Effect of 17 $\beta$-E2 on the expression level of LC3 in hFOB1.19 osteoblasts. (A) Western blotting showed the expression of LC3 protein in osteoblasts treated with $17 \beta-E 2\left(0,10^{-8}, 10^{-7}, 10^{-6} \mathrm{M}\right)$ for $24 \mathrm{~h}$. (B) Western blotting showed the expression of LC3 in osteoblasts treated with $10^{-6} \mathrm{M} 17 \beta-\mathrm{E} 2$ for different time $(0,2,4,24,36 \mathrm{~h})$. The histograms showed the relative expression level of LC3 normalized to $\beta$-actin, and the densitometry analysis of the blots were estimated by using the Image J Software. The data were expressed as the means \pm SD from 3 independent experiments. Statistically significance was evaluated using the Student's t-test. ${ }^{*} P<0.05$ vs. the control group was considered significant. 
of autophagy was detected by MDC staining. The MDC results suggested that the cells autophagy activity significantly increased in $17 \beta$-E2 $\left(10^{-6} \mathrm{M}\right)$ group, while it diminished in $17 \beta-\mathrm{E} 2+3-\mathrm{MA}$ group (Figure 3 ). Collectively, these results indicated that $17 \beta$-E2 could promote autophagy in hFOB1.19 osteoblasts.

\section{Up-regulation of SIRT1 induced by $17 \beta$-E2 promotes autophagy in osteoblasts}

This study further explored whether up-regulation of SIRT1 induced by $17 \beta-E 2$ could promote autophagy in
hFOB1.19 osteoblasts. The cells were preincubated with or without SRT1720 (a SIRT1 activator) [40] and EX527 (a SIRT1-specific inhibitor) [41] for $2 \mathrm{~h}$, and then they were incubated with $10^{-6} \mathrm{M} 17 \beta$-E2 for $24 \mathrm{~h}$. Immunofluorescence staining suggested that the expression of LC3 (marker of autophagy) in 17 $\beta$-E2 + SRT1720 group was significantly increased than that in the control group (Figure 4). However, the increasing effect was abolished in 17ß-E2 + EX527 group. TEM was considered to be an effective method to detect autophagy. TEM was served as a tool to observe the characteristics and quantify the number of

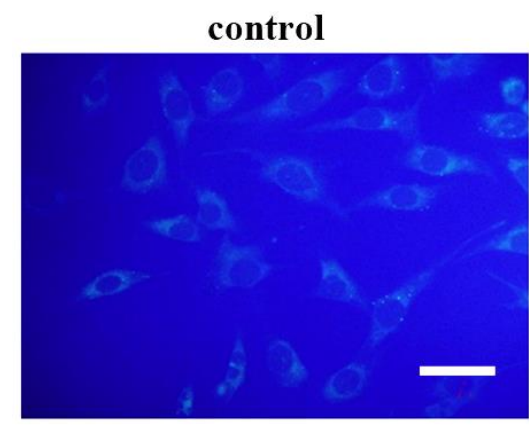

17ß-E2 $\left(10^{-6} \mathrm{M}\right)$
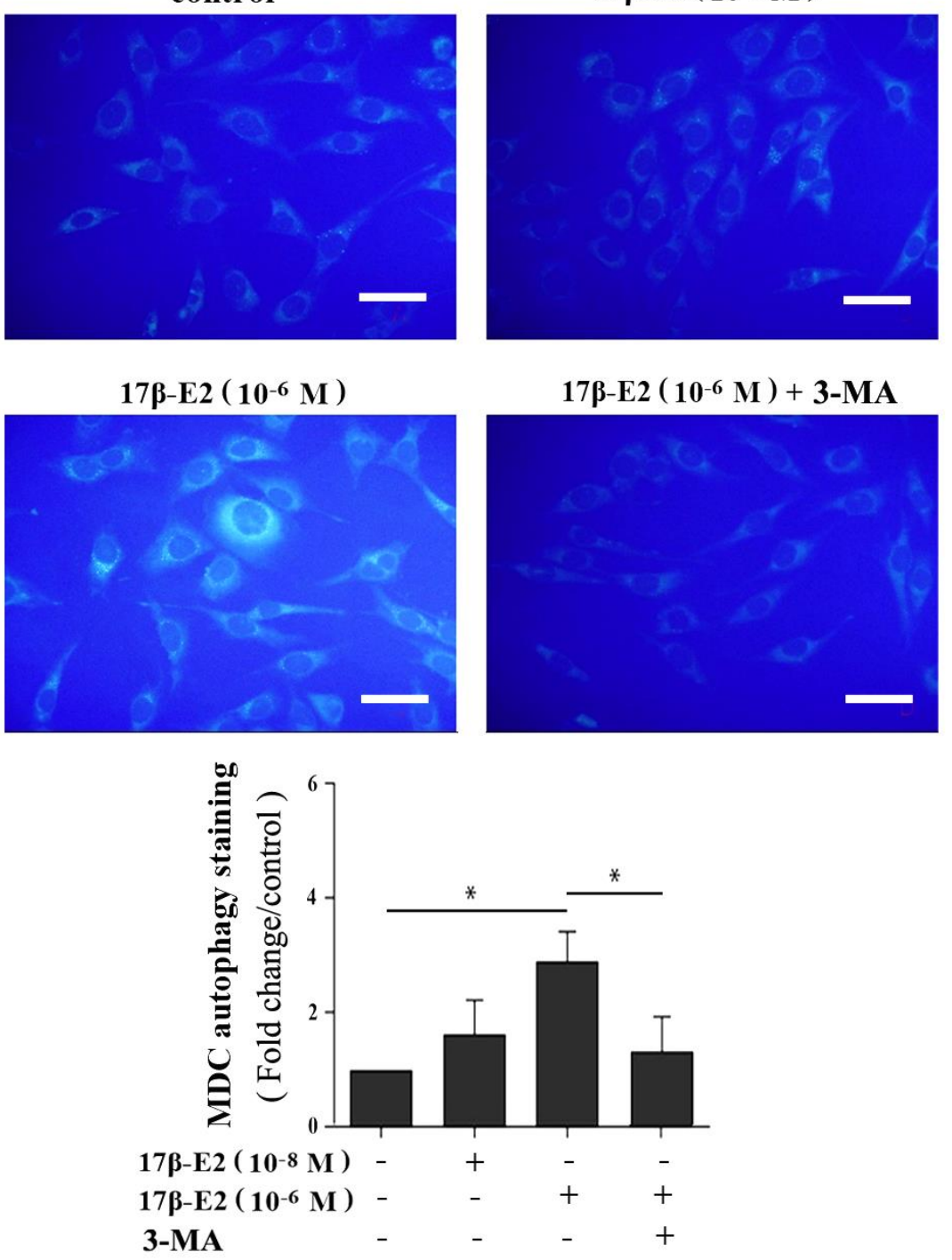

Figure 3. Assessment of autophagy regulated by $17 \beta-E 2$ in osteoblasts using monodansylcadaverine (MDC) staining. The osteoblasts were pretreated with or without 3-MA for $2 \mathrm{~h}$, and then cultured with $17 \beta-\mathrm{E} 2\left(0,10^{-8}, 10^{-6} \mathrm{M}\right)$ for $24 \mathrm{~h}$. Level of cell autophagy was evaluated by the intensity of fluorescent dots. The histogram showed that the relative intensity of fluorescent dots was significantly greater in $10^{-6} \mathrm{M} 17 \beta-\mathrm{E} 2$ group than in the control group and $17 \beta-\mathrm{E} 2\left(10^{-6} \mathrm{M}\right)+3-\mathrm{MA}$ group. Scale bar $=20 \mu \mathrm{m}$. The data were expressed as the means \pm SD from 3 independent experiments. Statistically significance was evaluated using the Student's t-test. * $P<0.05$ vs. the control group was considered significant. 


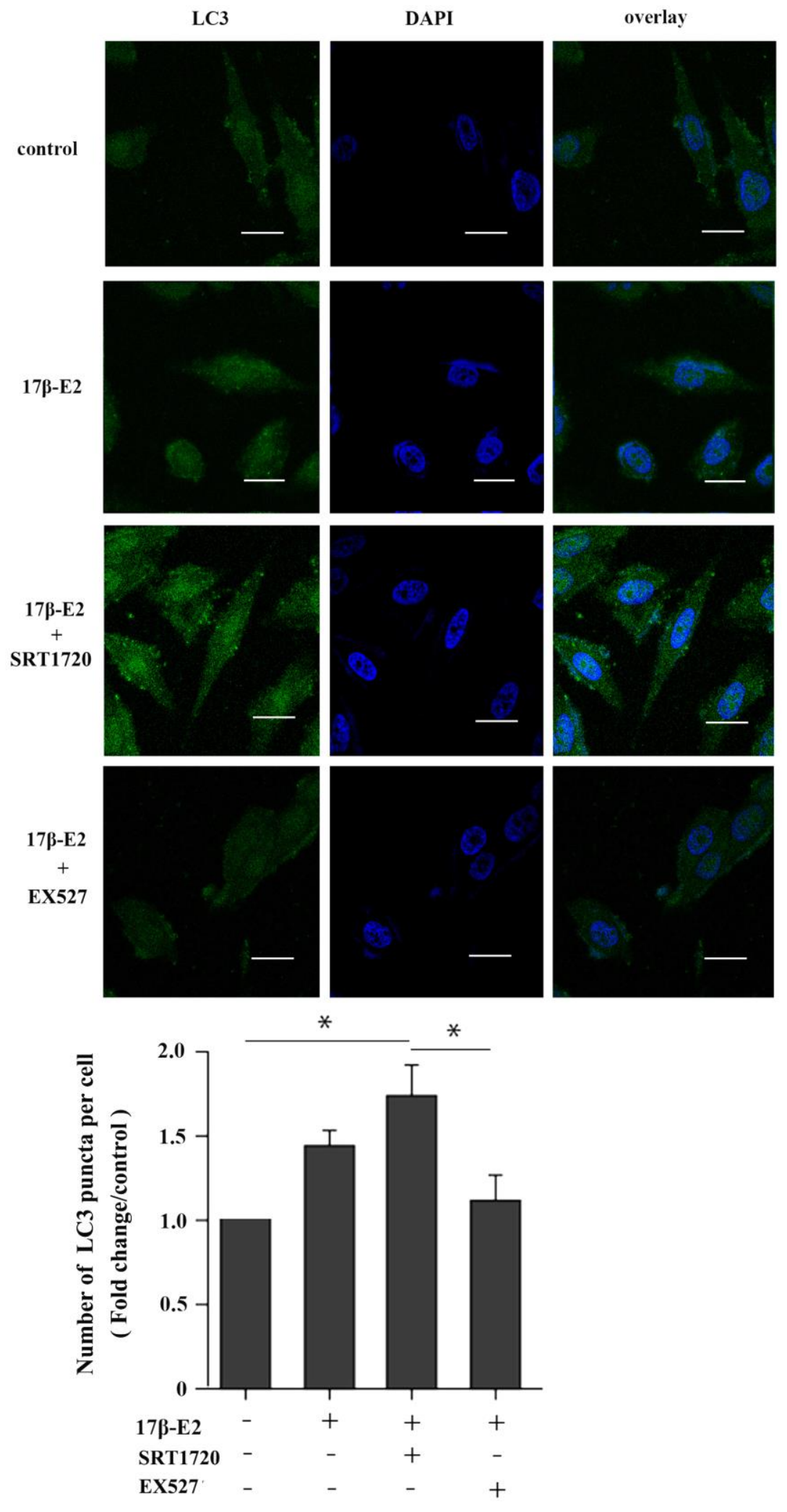

Figure 4. Effect of SIRT1 up-regulation induced by17 $\beta$-E2 on the expression of LC3 in hFOB1.19 osteoblasts. SRT1720 or EX527 regulated the expression of LC3 in 17 $\beta$-E2-treated osteoblasts, as determined using immunofluorescence staining. Nuclei were stained with DAPI (blue). Representative images and quantified analysis of immunofluorescence staining showing the LC 3 in cells. White bar $=50 \mu \mathrm{m}$. The histogram showed the number of LC3 puncta in various groups as indicated. The data were expressed as the means \pm SD from 3 independent experiments. Statistically significance was evaluated using the Student's t-test. ${ }^{*} P<0.05$ vs. the control group was considered significant. 
autophagosomes. The results showed that the number of autophagosomes in 17 $\beta$-E2 + SRT1720 group was significantly increased than that in control group while that in $17 \beta-\mathrm{E} 2+\mathrm{EX} 527$ group was significantly lower $(P<0.05)$, (Figure 5). To sum up, these results indicated that the $17 \beta$-E2 might induce SIRT1 up-regulation to promote autophagy in hFOB1.19 osteoblasts.
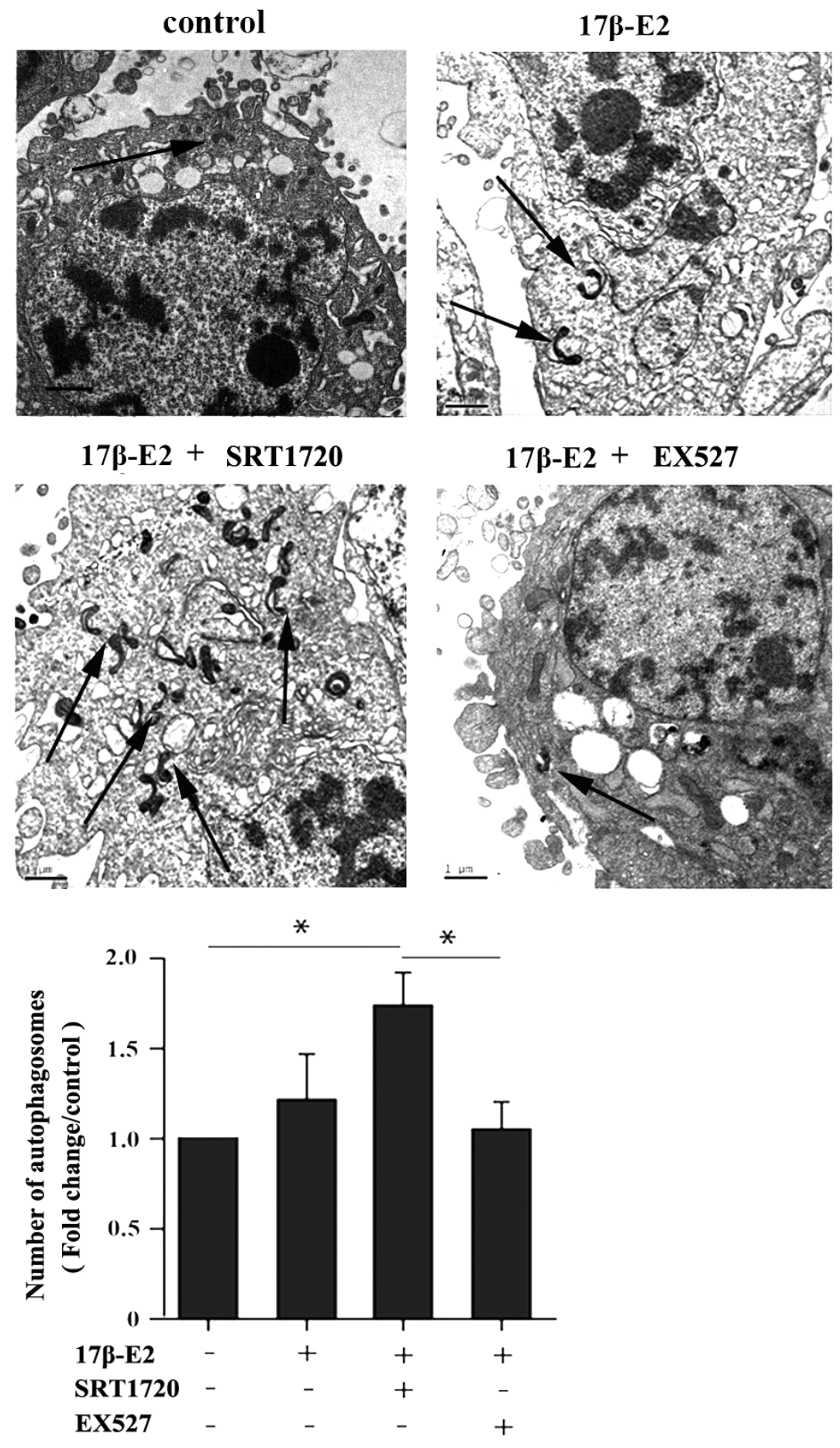

Figure 5. Effect of SIRT1 up-regulation induced by $17 \beta-E 2$ on cell autophagy in hFOB1.19 osteoblasts. TEM images showed more double-membrane vacuoles (autophagosomes) in cells treated with 17 $\beta$-E2 + SRT1720 compared with those in the control group and 17 $\beta$-E2 + EX527 group. The histogram showed the number of autophagosomes in different groups as indicated. The autophagic vacuoles are indicated with black arrows. Black bar: $1 \mu \mathrm{m} . * P<0.05$ vs. the control group was considered significant. 
Up-regulation of SIRT1 induced by 17ß-E2 inhibits apoptosis in osteoblasts

hFOB1.19 osteoblasts were pretreated with or without $10 \mu \mathrm{M}$ SRT1720 and $10 \mu \mathrm{M}$ EX527 for $2 \mathrm{~h}$, and then cultured with $10^{-6} \mathrm{M} 17 \beta-\mathrm{E} 2$ for $24 \mathrm{~h}$. Flow cytometry analysis using Annexin V-FITC/PI dual staining, quantitative RT-PCR and Western blot assay were applied to detect and quantify the level of apoptosis in hFOB1.19 cells. The apoptotic rate (Q2+Q3) decreased significantly in $17 \beta$-E2 + SRT1720 group, but increased in 17 $\beta$-E2 + EX527 group (Figure 6A, $6 \mathrm{~B})$. The cell viability (\%) in different groups was assessed by MTT assay (Figure 6C). The results suggested that the osteoblasts viability in $17 \beta-E 2+$ SRT1720 group increased significantly compared with the control group, however this effect disappeared when exposure to a SIRT1-specific inhibitor EX527. The RT-PCR and Western blot results suggested that the expression of pro-apoptotic caspase- 3 mRNA and protein decreased significantly, while the level of antiapoptotic Bcl-2 increased in 17 $\beta$-E2 + SRT1720 group compared with the control group (Figure 7A-7D). In short, the results suggested that up-regulation of SIRT1 induced by $17 \beta$-E2 inhibited apoptosis in hFOB1.19 osteoblasts.

\section{Up-regulation of SIRT1 induced by 17ß-E2 promotes autophagy and inhibits apoptosis in osteoblasts}

Our results showed that up-regulation of SIRT1 induced by $17 \beta-E 2$ promoted autophagy and inhibited apoptosis in osteoblasts. Here, in order to expound the molecular mechanisms of these processes, we measured the expression of the AMPK-mTOR and FOXO3a. Cells were precultured with or without SRT1720 and Ex527 prior to exposure to $10^{-6} \mathrm{M} 17 \beta$ E2 for $24 \mathrm{~h}$. The mRNA and protein expression levels of LC3, Beclin-1, caspase-3, Bcl-2, p-AMPK, FOXO3a, p-mTOR were measured by RT-PCR and Western blot assay. Compared with the control group, the expression level of LC3 (Figure 8A, 8B), Beclin-1 (Figure 8C, 8D) and p-AMPK (Figure 9B) increased remarkably in 17 $\beta$-E2 + SRT1720 group, however a robust decrease in p-mTOR (Figure 9C). Notably, this action could be abolished by the SIRT1-specific inhibitor Ex527 and hardly be turned backward by $17 \beta-E 2$. The expression of t-AMPK had no significant change in different groups (Figure 9A, 9B). The expression of caspase- 3 in 17 $\beta$-E2 + SRT1720 group was significantly decreased, yet a significantly increased in Bcl-2 compared with the control group (Figure 7A7D). EX527 treatment resulted in the opposite effects. In addition, compared with the control group, the FOXO3a expression was significantly activated in $17 \beta-$ $\mathrm{E} 2+\mathrm{SRT} 1720$ group, while the expression of FOXO3a
A
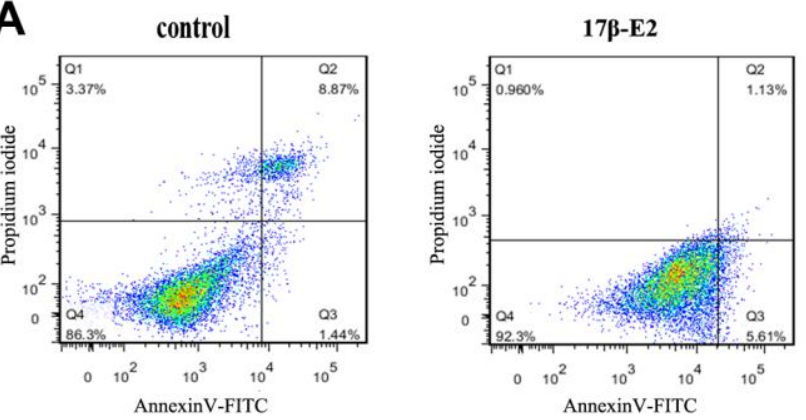

17ß-E2 + SRT1720
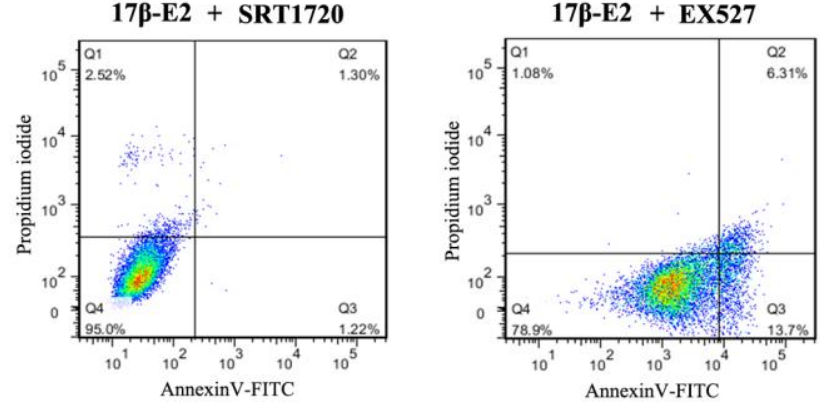

B
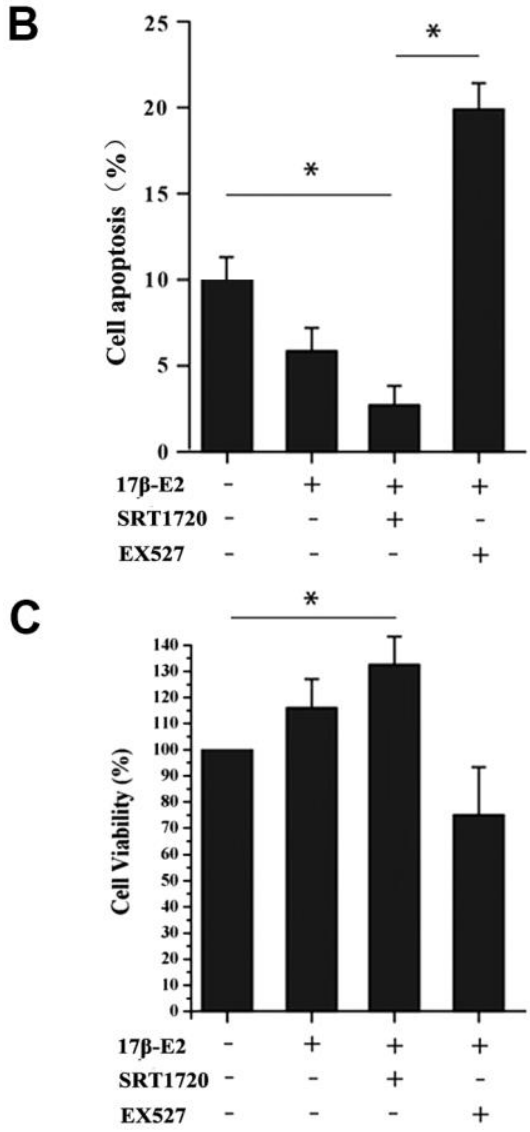

Figure 6. Up-regulation of SIRT1 induced by $17 \beta-E 2$ inhibited apoptosis in osteoblasts. (A) Cell apoptosis rates (\%) were measured by using flow cytometry (FCM) analysis of Annexin V-FITC/PI dual staining in osteoblasts pretreated with or without SRT1720 and EX527 for $2 \mathrm{~h}$ prior to incubation with $17 \mathrm{\beta}$ E2 $\left(10^{-6} \mathrm{M}\right)$ for $24 \mathrm{~h}$. Q1, dead cells; Q2, later apoptotic cells; Q3, 
early apoptotic cells; Q4, living cells. The apoptotic rate was determined as the percentage of Q2+Q3. (B) The histogram showed the percentage of apoptosis rate in different groups. The results suggested that the apoptosis rates $\left(Q_{2}+Q_{3}\right)$ were significantly decreased in $17 \beta-E 2+$ SRT1720 group compared with those in the control group and $17 \beta-E 2+$ EX527 group. (C) MTT assay was performed to detect the osteoblasts viability, and the histogram showed the cell viability (\%) in different groups. The data were expressed as the means \pm SD from 3 independent experiments. $* P<0.05$ vs. the control group was considered significant. reduced in 17ß-E2 + EX527 group (Figure 8E, 8F). Collectively, the results suggested that up-regulation of SIRT1 induced by $17 \beta-E 2$ to promote autophagy and inhibit apoptosis may be associated with AMPK-mTOR and FOXO3a pathways, respectively (Figure 10).

\section{DISCUSSION}

Postmenopausal osteoporosis (PMO) is the most common type of osteoporosis caused by estrogen
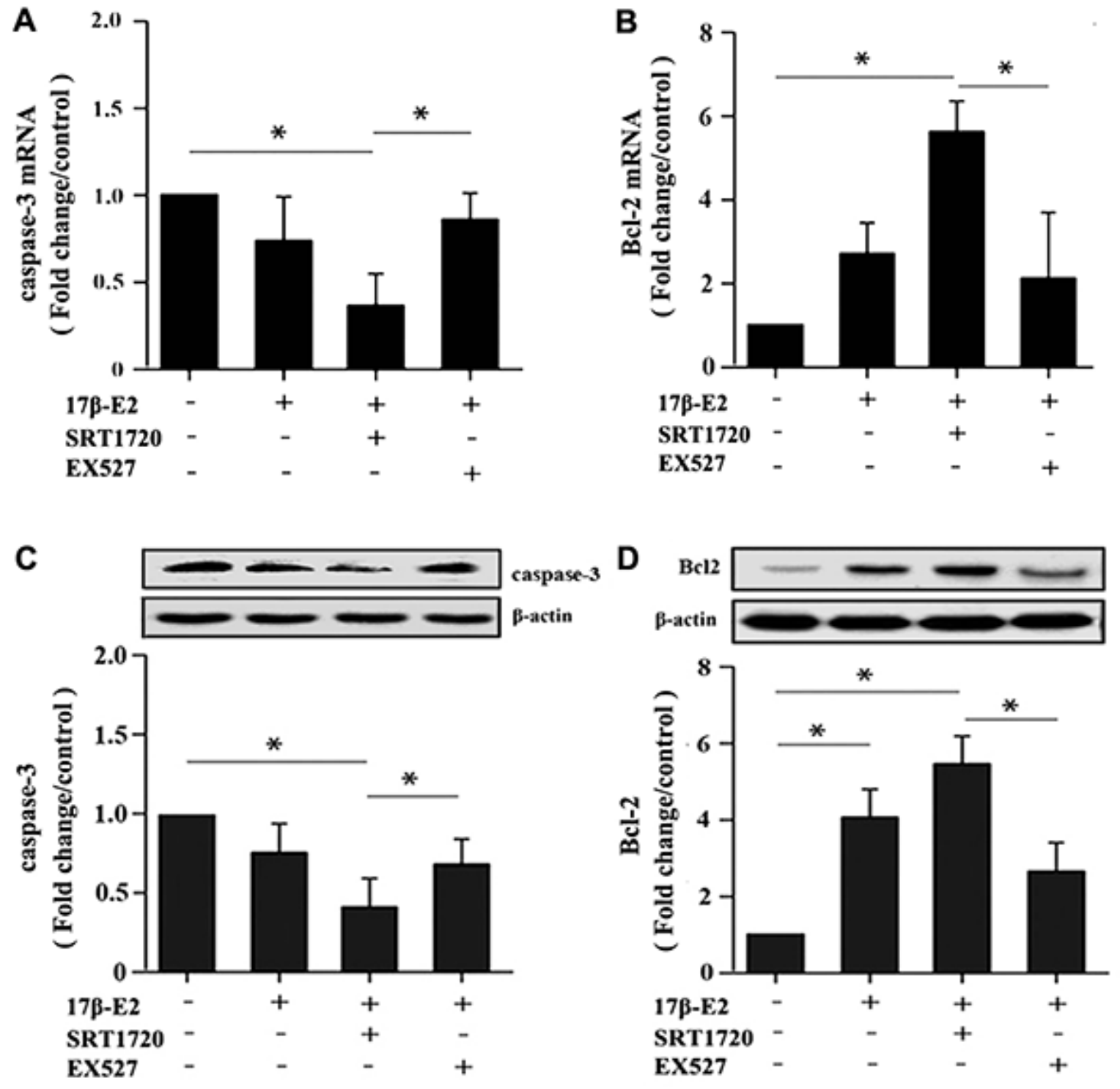

Figure 7. Detection of caspase-3 and Bcl-2 expression in hFOB1.19 osteoblasts by real-time PCR and Western blot assay. Cells were pretreated with or without SRT1720 and EX527 for $2 \mathrm{~h}$, and then cultured with 17ß-E2 (10-6 M) for $24 \mathrm{~h}$. The expression of caspase-3 (A) and Bcl-2 (B) mRNA in osteoblasts were assessed by RT-PCR. The data were normalized to GAPDH. The expression level of caspase-3 (C) and $\mathrm{BCl}-2$ (D) proteins in osteoblasts were measured by Western blotting. The histograms showed the relative protein expression of caspase-3 (C) and $\mathrm{Bcl}-2$ (D) normalized to $\beta$-actin protein, and the densitometry analysis of the blots were estimated by using the Image J Software. The data were expressed as the means \pm SD from 3 independent experiments. Statistically significance was evaluated using the Student's t-test. * $P<0.05$ vs. the control group was considered significant. 
A

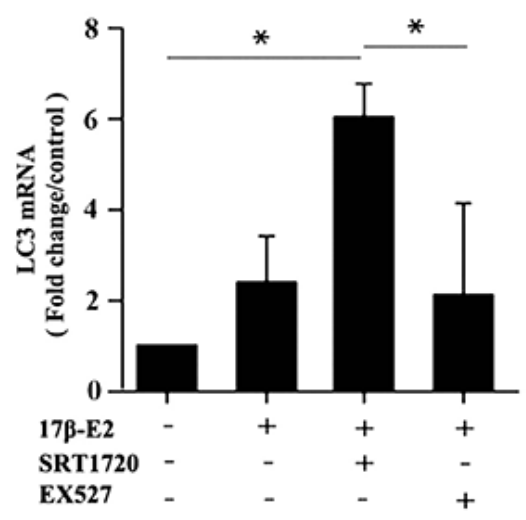

B

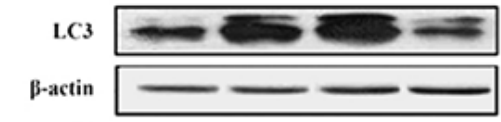

C

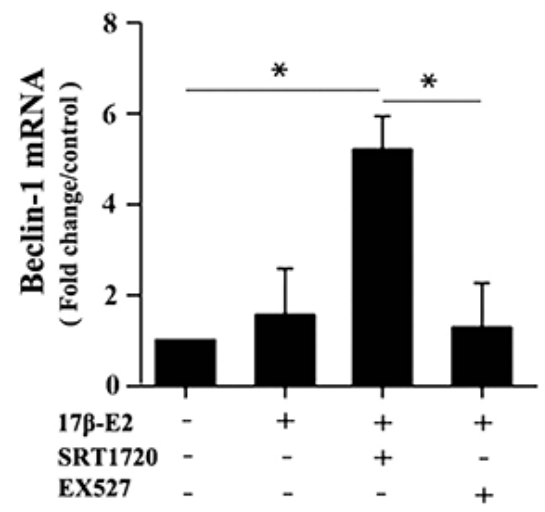

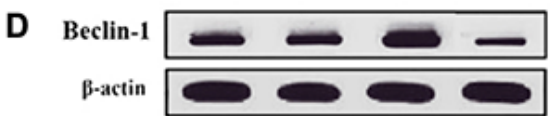

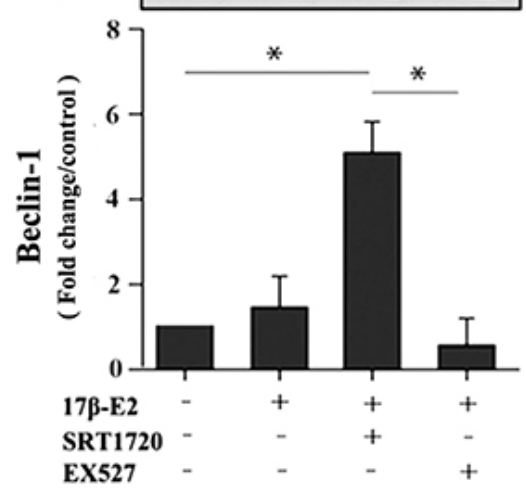

$\mathbf{F}$

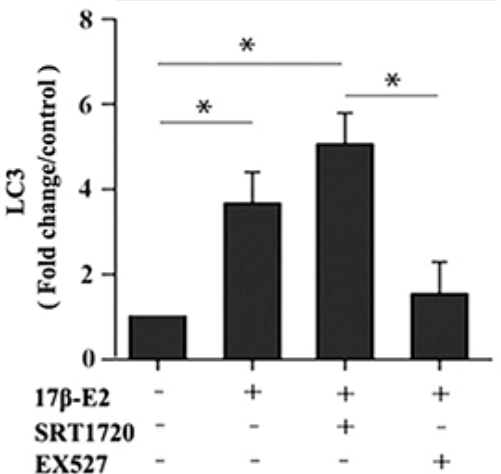

E
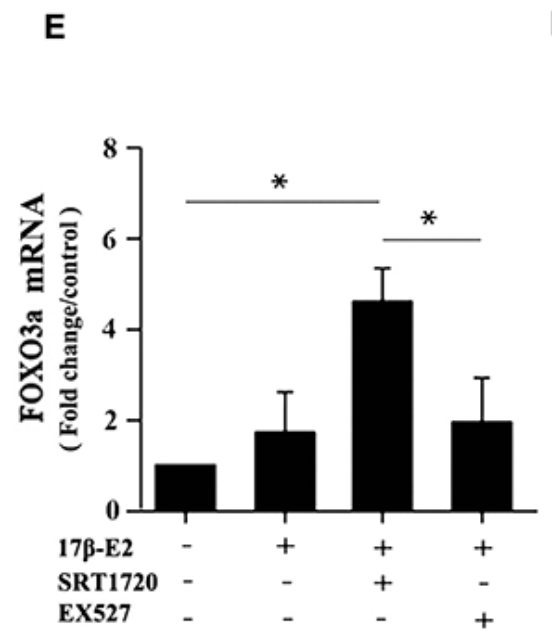
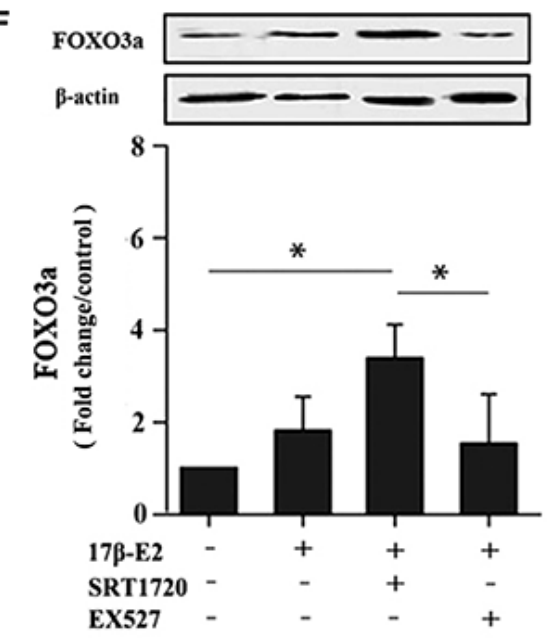

Figure 8. Real-time PCR and Western blotting showing the expression of LC3, Beclin-1 and FOXO3a in hFOB1.19 osteoblasts. Cells were pretreated with or without SRT1720 and EX527 for $2 \mathrm{~h}$, and then cultured with 17ß-E2 (10-6 M) for $24 \mathrm{~h}$. RT-PCR and Western blot assay showed the expression of LC3 (A, B), Beclin-1 (C, D) and FOXO3a (E, F) mRNA and proteins in osteoblasts. The mRNA data were normalized to GAPDH. The histograms showed the relative proteins expression of LC3, Beclin-1 and FOXO3a normalized to $\beta$-actin, and the densitometry analysis of the blots were estimated by using the Image J Software. The data were expressed as the means \pm SD from 3 independent experiments. Statistically significance was evaluated using the Student's t-test. ${ }^{*} \mathrm{P}<0.05$ vs. the control group was considered significant. 

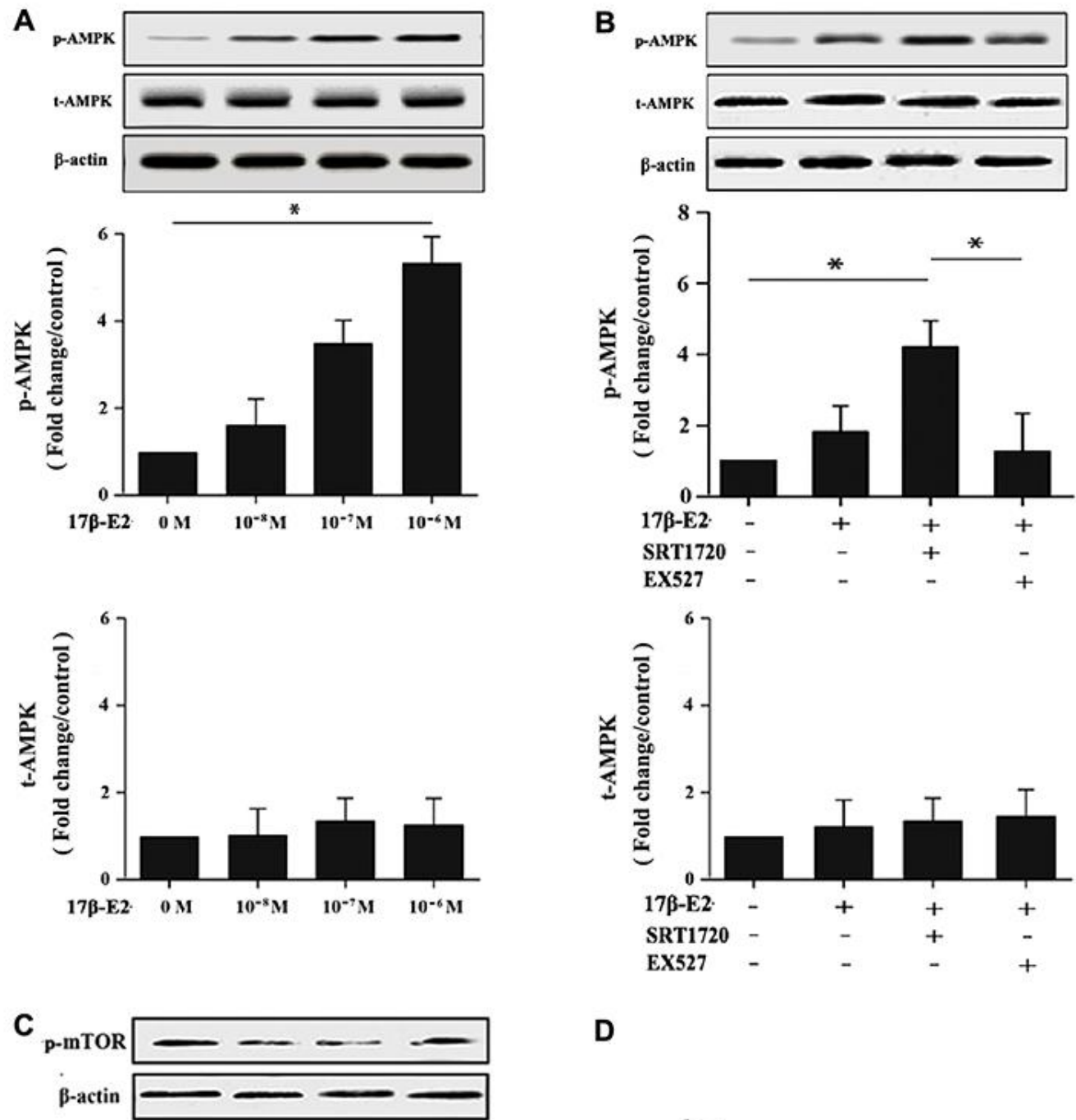

D
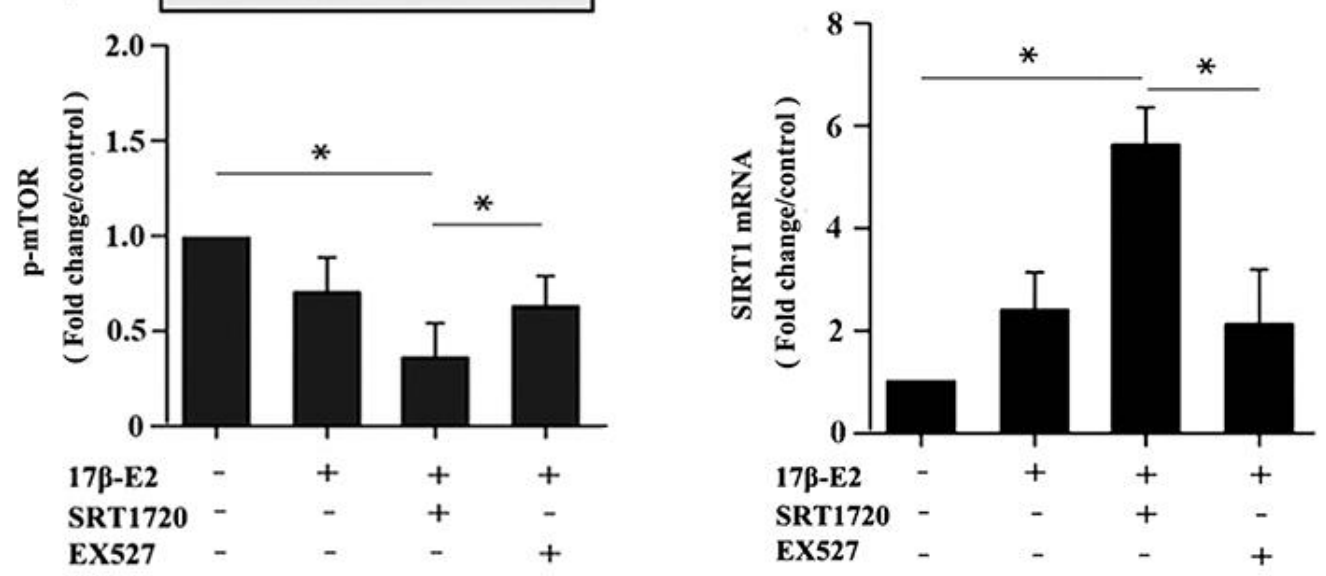

Figure 9. Up-regulation of SIRT1 induced by 17 $\beta$-E2 promoted autophagy in osteoblasts via AMPK-mTOR pathway. Western blotting showed the expression of p-AMPK, t-AMPK, p-mTOR and $\beta$-actin in osteoblasts among the groups. (A) The expression level of AMPK phosphorylation in osteoblasts treated with $17 \beta-\mathrm{E} 2\left(0,10^{-8}, 10^{-7}, 10^{-6} \mathrm{M}\right)$ for $24 \mathrm{~h}$. Cells were pretreated with or without SRT1720 and EX527 for $2 \mathrm{~h}$, and then cultured with $17 \beta-\mathrm{E} 2\left(10^{-6} \mathrm{M}\right)$ for $24 \mathrm{~h}$. Western blotting showed the expression of p-AMPK (B), and p-mTOR (C) proteins in osteoblasts. The histograms showed the relative expression of p-AMPK and p-mTOR normalized to $\beta$-actin, and the densitometry analysis of the blots were estimated by using the Image J Software. The expression ofSIRT1 (D) mRNA in osteoblasts were measured by RT-PCR. The data were expressed as the means \pm SD from 3 independent experiments. Statistically significance was evaluated using the Student's t-test. ${ }^{*} P<$ 0.05 vs. the control group was considered significant. 
deficiency in clinic [42]. The lack of estrogen has detrimental effects on all types of bone cells, especially osteoblasts, resulting in an increase in the level of bone turnover [42]. Many studies have shown that ERalpha plays a central role in the osteoprotective effects of $17 \beta$ E2 [14, 43, 44]. Vinel et al. indicated that ERalpha is necessary for the protective effects of $17 \beta$-E2 in the alveolar, trabecular and cortical bone of the mandible, while ERbeta is not indispensable [45]. Khan et al. reported that $17 \beta-E 2$ positively regulates SIRT1 through ERalpha, thereby reducing memory loss in adult mice mediated by oxidative stress, neurodegeneration and neuroinflammation [46]. This study suggested that exposure to $17 \beta-E 2$ induced up-regulation of SIRT1 in hFOB1.19 osteoblasts, leading to a promotion in cell autophagy and inhibition in cell apoptosis. Furthermore, our data showed that the effect of SIRT1 up-regulation positively regulated AMPK and FOXO3a, but inhibited mTOR. It is reported that the AMPK-mTOR signaling pathway regulates autophagy [47] and FOXO3a participates in apoptosis [35]. Autophagy and apoptosis play significant roles in osteoporosis [27]. Therefore, we could hypothesize that the up-regulation of SIRT1 induced by $17 \beta-E 2$ protected against osteoporosis, at least in part, by promoting autophagy via AMPKmTOR pathway and by inhibiting apoptosis via FOXO3a activation (Figure 10).

SIRT1, the mammalian homologue 1 of silent information regulator 2, plays important roles in the regulation of multiple biological processes, including bone metabolism, autophagy, apoptosis, and aging [20, 25, 48, 49]. Accumulating evidence has demonstrated that SIRT1 has a crucial effect in anti-osteoporosis through a complex signaling network, including autophagy [20] and apoptosis [50]. Zainabadi et al. reported that SIRT1 is not only a positive regulating factor of bone mass in vivo, but also a therapeutic target for osteoporosis [22]. In our experiments, the data suggested that $17 \beta$-E2 induced up-regulation of SIRT1 in hFOB1.19 osteoblasts. We also observed that up-regulation of SIRT1 participated in the promotion of osteoblasts

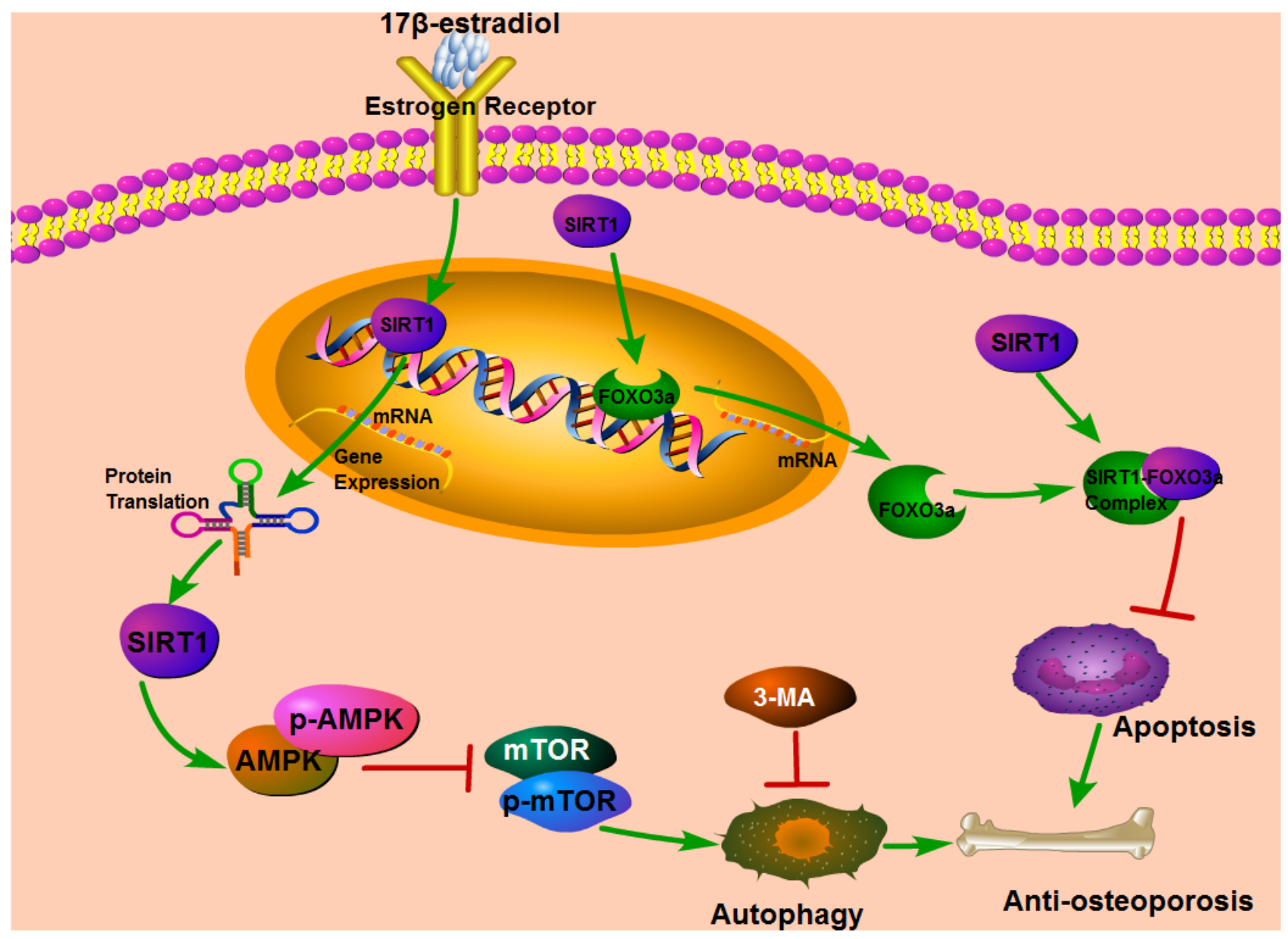

Figure 10. The diagram describes the underlying mechanism that the up-regulation of SIRT1 induced by $17 \beta$-E2 could promote autophagy via the AMPK-mTOR pathway and inhibit apoptosis by the FOXO3a activation. 
autophagy. $\mathrm{Gu}$ et al. reported that SIRT1 protects osteoblasts from fluoride toxicity through the induction of autophagy [51]. Several studies also have reported that $17 \beta$-E2 can upregulate SIRT1 expression and play a beneficial role in osteoblasts [52, 53], which is accordance with our results. AMPK was regarded as a significant pathway of regulating cellular energy and metabolism homeostasis $[54,55]$. It is well established that AMPK activation inhibits mTOR, thus promoting autophagy $[32,56]$. The present study demonstrated that up-regulation of SIRT1 might activate AMPK and inhibit mTOR in osteoblasts under $17 \beta$-E2-induced conditions, and that the autophagy regulation effect of AMPK-mTOR signaling was attenuated when EX527 was added. Wang et al. demonstrated that tetramethylpyrazine could promote autophagy and protect bone marrow mesenchymal stem cells (BMSCs) from exposure to excessive glucocorticoids by the AMPK-mTOR signaling pathway [29]. Taken together, we hypothesized that up-regulation of SIRT1 induced by $17 \beta-E 2$ could promote osteoblasts autophagy, which might be related to the AMPK-mTOR pathway.

Multiple lines of evidence have demonstrated that osteoblast apoptosis played an unfavorable role in the occurrence and progression of osteoporosis [42, 57, 58]. As is known to all, the anti-apoptosis ability of SIRT1 is self-evident $[25,51,59]$. Several studies showed that moderate SIRT1 overexpression could be effective in preventing drug induced apoptosis and oxidative stress $[33,60,61]$. In this study, the results suggested that upregulation of SIRT1 induced by $17 \beta$-E2 inhibited apoptosis in hFOB1.19 osteoblasts. Yao et al. also reported that moderate overexpression of SIRT1 might suppress osteoblasts apoptosis through FOXO1/ $\beta$ catenin pathway [25]. Forkhead box O (FOXO) transcriptional factor plays a significant role in bone metabolism by anti-apoptosis and anti-oxidative stress $[62,63]$. FOXO3a, an important member of the FOXO family, is of special interest as it is the dominant subtype expressed in bone tissue [64]. SIRT1 deacetylates various transcription factors, including FOXO3a, thus playing significant roles in antiapoptosis, metabolism and cell differentiation [35, 36, 64]. The present study suggested that up-regulation of SIRT1 increased FOXO3a and $\mathrm{Bcl}-2$ expression, but decreased caspase-3 expression. Therefore, it is speculated that the up-regulation of SIRT1 induced by 17ß-E2 might inhibit apoptosis in osteoblasts via FOXO3a activation. In this study, we demonstrated that the 17 $\beta$-E2 administration could induce up-regulation of SIRT1 expression. Moreover, these findings suggested that the up-regulation of SIRT1 induced by $17 \beta$-E2 has the potential to protect against osteoporosis, and that the beneficial effect of SIRT1 depend, at least in part, on promoting osteoblasts autophagy via AMPK-mTOR pathway and inhibiting cell apoptosis via FOXO3a activation. Meanwhile, our findings presented a new visual angle and idea on the mechanism of SIRT1 in osteoporosis, and 17 $\beta$-E2 combined with SIRT1 might represent a potential therapeutic target for osteoporosis. However, there are some limitations. Firstly, only one cell line hFOB1.19 was utilized in vitro. Secondly, we did not completely elucidate how SIRT1 regulates AMPK-mTOR and FOXO3a and the interactions between autophagy and apoptosis, therefore, further studies are needed.

\section{MATERIALS AND METHODS}

\section{Cell culture and treatments}

hFOB1.19 osteoblasts are bought from ATCC (Manassas, VA, USA). The cells were incubated with $10 \%$ FBS in $\alpha$-MEM/F12 medium (Invitrogen, MA, USA) at $37^{\circ} \mathrm{C}$ in $5 \% \mathrm{CO}_{2}$ and humidified atmosphere. 17 $\beta$-E2 (Sigma, MO, USA) was prepared with different concentrations. Under normal cell growth conditions, they were subjected to $17 \beta$-E2 $\left(0,10^{-8}, 10^{-7}, 10^{-6} \mathrm{M}\right)$ for a prescribed time period $(0,2,4,24$, and $32 \mathrm{~h})$. In combined administration, cells were precultured with the corresponding agonists or specific inhibitors for $2 \mathrm{~h}$, and then treated with the optimal dosage $\left(10^{-6} \mathrm{M}\right)$ of $17 \beta$-E2 for $24 \mathrm{~h}$. SIRT1 selective activator (SRT1720) was used at $10 \mu \mathrm{M}[65,66]$, SIRT1-specific inhibitor (EX527) at $10 \mu \mathrm{M}[67,68]$, autophagy inhibitor (3-MA) at $10 \mathrm{mM}$ [69].

\section{Monodansylcadaverine (MDC) staining}

MDC is called autophagy vacuoles specific probe, which is used to label autophagy-lysosomes [70-72]. The formation of autophagy vesicles is a hallmark of autophagy, marked by MDC and shown as bright color dots under a fluorescence microscopy [73]. MDC staining test was used for autophagy acidic vacuoles. The osteoblasts in the logarithmic growth phase were used, adjusted the cell density to inoculate $1 \times 10^{5}$ cells $/ \mathrm{mL}$ in the climbing slides in 24-well plates, cultured for $24 \mathrm{~h}$. Osteoblasts were cultured with or without autophagy inhibitor 3-MA $(10 \mathrm{mM})$ for $2 \mathrm{~h}$ followed by $17 \beta$-E2 $\left(10^{-8}\right.$ or $\left.10^{-6} \mathrm{M}\right)$ for $24 \mathrm{~h}$ [74]. The acidic vacuoles were rinsed with PBS three times, soaked in 4\% PFA solution for $20 \mathrm{~min}, 0.05 \mathrm{mM}$ MDC solution was added to each well, then cultured at $37^{\circ} \mathrm{C}$ for $1 \mathrm{~h}$. Removed the MDC solution and rinsed with PBS 3 times. Then the slides were taken out and 3 visual fields were randomly selected under the fluorescence microscope (Olympus, Japan) to observe and take pictures, followed by analyzing the average relative fluorescence intensity with Image-Proclus 6.0 software. 


\section{Immunofluorescence analysis}

Immunofluorescence analysis of LC3 was performed as described previously [75]. Appropriate number of cells was cultivated in a confocal culture dish for $24 \mathrm{~h}$. Cells were rinsed with PBS for three times. The osteoblasts were then soaked in 4\% PFA for thirty min. After rinsing with PBS, cells were blocked at the non-lipid antibody site with 5\% BSA in TBST. The membranes were cultured overnight at $4^{\circ} \mathrm{C}$ with specific rabbit anti-human LC3 (1: 200) primary antibodies. Then they were incubated with goat anti-rabbit IgG-HRP (1:3000, Sigma Inc., MO, USA) secondary antibody. After rinsing three times, they were observed under fluorescence microscope and the confocal laser scanning microscope (Olympus Optical Co., Ltd., Japan). Then the number of LC3 puncta was measured using Image J Software 1.48 (ML, USA).

\section{Transmission electron microscopy (TEM) observation}

To detect autophagosomes, TEM remains the best and most powerful approach [76]. TEM analysis was conducted as described previously [77]. The osteoblasts were harvested and fixed in $2.5 \%$ glutaraldehyde in PBS buffer, then fixed in $1 \%$ osmium tetroxide in pure water for one hour. After gradient ethanol dehydration, the cells were embedded and sectioned. The samples were double-stained with uranyl acetate and lead citrate. Then, the autophagosomes of osteoblasts were observed under a Transmission Electron Microscopy (JEOL Ltd., Japan). The number of autophagosomes was determined using Image J Software 1.48 (ML, USA).

\section{MTT assay}

Osteoblasts were cultured in 96-well plates at a cell density of $10^{4}$ cells per well. After attachment, cells were precultured with or without SRT1720 $(10 \mu \mathrm{M})$ and EX527 $(10 \mu \mathrm{M})$ for $120 \mathrm{~min}$ [65-68]. Then osteoblasts were incubated with $0 \mathrm{M}$ or $10^{-6} \mathrm{M} 17 \beta$-E2 for 24 hours, $10 \mu \mathrm{L}$ MTT reagent $(5 \mathrm{mg} / \mathrm{mL})$ at $37^{\circ} \mathrm{C}$ for $3 \mathrm{~h}$, and then cultured with dimethyl sulfoxide (DMSO) instead of culture medium for $4 \mathrm{~h}$. Optical density was recorded using a microplate reader (Reagan Ltd., USA) at $490 \mathrm{~nm}$.

\section{Cell apoptosis analysis}

Osteoblasts apoptosis was determined by an Annexin V-FITC/PI apoptosis detection kit, and it was deployed according to the manufacturer's protocols [78]. In short, cells $\left(5 \times 10^{5}\right.$ cells/ sample) were collected, washed two times with PBS, and suspended in $500 \mu$ binding buffer. Then samples were cultured with $5 \mu \mathrm{L}$ of Annexin V-FITC and $5 \mu \mathrm{L}$ PI solution at ambient temperature for fifteen min, and then immediately subjected to flow cytometry analysis using a flow cytometer (FACSCanto II, BD Biosciences, USA).

\section{RNA extraction, cDNA synthesis and real-time PCR assay}

The mRNA level of SIRT1, LC3, Beclin-1, caspase-3, Bcl-2, FOXO3a in hFOB1.19 osteoblasts were detected by real-time PCR. Previous studies have shown that GAPDH mRNA expression is not regulated by $17 \beta$-E2 treatment $[79,80]$. According to manufacturer's instructions, total RNA was extracted from hFOB1.19 osteoblasts using TRIzol reagent (Invitrogen, USA). The RevertAid First-Strand cDNA Synthesis Kit (Thermo Scientific ${ }^{\mathrm{TM}}$, USA) was applied to reversetranscribe RNA into cDNA. Then, using cDNA as template, the appropriate specific primers and real-time PCR kit (Takara Inc., China) were used to detect the mRNA level. The specific primer sequences of SIRT1, caspase-3, LC3, FOXO3a, Bcl-2 and Beclin-1 were listed in Table 1. GAPDH was used for normalization and served as the internal reference. The relative mRNA expression levels were quantitated using the $2^{-\Delta \Delta \mathrm{Ct}}$ method.

\section{Protein preparation and Western blot analysis}

After administration, hFOB1.19 osteoblasts were lysed with NP-40 lysis buffer and the extracts were centrifuged to collect the supernatant containing total protein. Then a Pierce BCA Protein Assay Kit (Thermo Scientific ${ }^{\mathrm{TM}}$, USA) was applied to measure the protein concentration, according to the manufacturer's instructions [81]. The protein samples were separated by SDS-PAGE gels (10\% SDS)for $100 \mathrm{~min}$ at $110 \mathrm{~V}$ and transferred to a PVDF membrane [82]. Then, the membranes were blocked for one hours using 5\% skim milk/ BSA at ambient temperature and incubated with primary antibodies (SIRT1, AMPK, p-AMPK, LC3, Bcl-2, caspase-3, Beclin-1, p-mTOR (Ser2448) and $\beta$ actin antibodies) at $4^{\circ} \mathrm{C}$ overnight. Phosphorylation of the m-TOR Ser2448 site is a direct target of the anti-pmTOR antibody. Then, the membranes were incubated with corresponding secondary antibodies for $60 \mathrm{~min}$ at ambient temperature. The BeyoECL plus kit (Beyotime Bio Ltd., China) was used to visualize the proteins. $\beta$ actin was used as an internal reference. The bands densitometric analysis was measured by Image $\mathbf{J}$ Software 1.48 (ML, USA) [83].

\section{Statistical analysis}

Results were represented as means \pm standard deviation (S.D.). The experiments were repeated three times independently. Statistical significance was analyzed by Student's t-test, one-way Analysis of Variance 
Table 1. Primer and probe sequences of all genes used in RT-PCR.

\begin{tabular}{lcc}
\hline Primers & Forward primer $\left(\mathbf{5}^{\prime} \mathbf{-} \mathbf{3}^{\prime}\right)$ & Reverse primer $\left(\mathbf{5}^{\prime} \mathbf{-} \mathbf{3}^{\prime}\right)$ \\
\hline SIRT1 & GTTGTGTGCCTTCGTTTTGGA & AGGCCGGTTTGGCTTATACA \\
LC3 & CTCTCTGAGCCTTAGGTGCC & ACTCGTGGGGTGACCATTTC \\
Beclin-1 & GAATGGAGGGGTCTAAGGCG & CCTCTTCCTCCTGGCTCTCT \\
caspase-3 & GATGTGGACGCAGCCAACCTCA & TCCGGCAGTCGCCTCTGAA \\
FOXO3a & CGTTGTTGGTTTGAATGTGGG & GGTTTTCTCTGTAGGTCTTCCG \\
GAPDH & AGTCTACTGGCGTCTTCACC & CCACGATGCCAAAGTTGTCA \\
\hline
\end{tabular}

(ANOVA), followed by Student-Newman-Keuls test. $P<0.05$ was represents statistically significant difference. Statistical analysis was performed with the assistance of SPSS 15.0 Software (SPSS, Inc., USA) for Microsoft Windows.

\section{AUTHOR CONTRIBUTIONS}

LG contributed to the conception of the project. YW and RM contributed to the design of the project. YW, SH, PL and PW performed experiments, data acquisition and analysis. RM, YA and LG performed manuscript preparation and revision. LG and LG contributed to manuscript revision. All authors read and agreed to the final manuscript.

\section{CONFLICTS OF INTEREST}

The authors declare no conflicts of interest.

\section{FUNDING}

This work was supported by the National Natural Science Foundation of China (No. 81971322) and the Special Innovation Fund for Postgraduates of Jiangxi Province (No. YC2020-B044).

\section{REFERENCES}

1. Ensrud KE, Crandall CJ. Osteoporosis. Ann Intern Med. 2017; 167:ITC17-32. https://doi.org/10.7326/AITC201708010 PMID:28761958

2. Porter JL, Varacallo M. Osteoporosis. In: StatPearls. Treasure Island (FL): StatPearls Publishing. 2021. PMID:28722930

3. Compston JE, McClung MR, Leslie WD. Osteoporosis. Lancet. 2019; 393:364-76. https://doi.org/10.1016/S0140-6736(18)32112-3 PMID:30696576

4. Reid IR. A broader strategy for osteoporosis interventions. Nat Rev Endocrinol. 2020; 16:333-39. https://doi.org/10.1038/s41574-020-0339-7
PMID:32203407

5. Black DM, Rosen CJ. Clinical Practice. Postmenopausal Osteoporosis. N Engl J Med. 2016; 374:254-62. https://doi.org/10.1056/NEJMcp1513724 PMID:26789873

6. Zhang $\mathrm{P}$, Zhang $\mathrm{H}$, Lin J, Xiao $\mathrm{T}, \mathrm{Xu} \mathrm{R}, \mathrm{Fu} \mathrm{Y}$, Zhang $\mathrm{Y}, \mathrm{Du}$ $Y$, Cheng J, Jiang $H$. Insulin impedes osteogenesis of BMSCs by inhibiting autophagy and promoting premature senescence via the TGF- $\beta 1$ pathway. Aging (Albany NY). 2020; 12:2084-100. https://doi.org/10.18632/aging.102723 PMID:32017705

7. Ettinger $B$, Genant HK, Steiger $P$, Madvig P. Low-dosage micronized 17 beta-estradiol prevents bone loss in postmenopausal women. Am J Obstet Gynecol. 1992; 166:479-88.

https://doi.org/10.1016/0002-9378(92)91653-r PMID: 1536215

8. Chow J, Tobias JH, Colston KW, Chambers TJ. Estrogen maintains trabecular bone volume in rats not only by suppression of bone resorption but also by stimulation of bone formation. J Clin Invest. 1992; 89:74-78. https://doi.org/10.1172/JCI115588 PMID:1729283

9. Prestwood KM, Kenny AM, Kleppinger A, Kulldorff M. Ultralow-dose micronized 17beta-estradiol and bone density and bone metabolism in older women: a randomized controlled trial. JAMA. 2003; 290:1042-48. https://doi.org/10.1001/jama.290.8.1042 PMID: 12941676

10. Fuentes N, Silveyra P. Estrogen receptor signaling mechanisms. Adv Protein Chem Struct Biol. 2019; 116:135-70.

https://doi.org/10.1016/bs.apcsb.2019.01.001 PMID: $\underline{31036290}$

11. Valéra MC, Fontaine $C$, Dupuis $M$, Noirrit-Esclassan $E$, Vinel A, Guillaume M, Gourdy P, Lenfant F, Arnal JF. Towards optimization of estrogen receptor modulation in medicine. Pharmacol Ther. 2018; 189:123-29. https://doi.org/10.1016/j.pharmthera.2018.05.002 PMID:29730442 
12. Cooke PS, Nanjappa MK, Ko C, Prins GS, Hess RA. Estrogens in Male Physiology. Physiol Rev. 2017; 97:995-1043.

https://doi.org/10.1152/physrev.00018.2016

PMID:28539434

13. Couse JF, Lindzey J, Grandien K, Gustafsson JA, Korach KS. Tissue distribution and quantitative analysis of estrogen receptor-alpha (ERalpha) and estrogen receptor-beta (ERbeta) messenger ribonucleic acid in the wild-type and ERalpha-knockout mouse. Endocrinology. 1997; 138:4613-21.

https://doi.org/10.1210/endo.138.11.5496 PMID:9348186

14. Sims NA, Clément-Lacroix $P$, Minet $D$, Fraslon-Vanhulle C, Gaillard-Kelly M, Resche-Rigon M, Baron R. A functional androgen receptor is not sufficient to allow estradiol to protect bone after gonadectomy in estradiol receptor-deficient mice. J Clin Invest. 2003; 111:1319-27. https://doi.org/10.1172/JCI17246 PMID:12727923

15. Sims NA, Dupont S, Krust A, Clement-Lacroix P, Minet D, Resche-Rigon M, Gaillard-Kelly M, Baron R. Deletion of estrogen receptors reveals a regulatory role for estrogen receptors-beta in bone remodeling in females but not in males. Bone. 2002; 30:18-25.

https://doi.org/10.1016/s8756-3282(01)00643-3 PMID:11792560

16. Dupont S, Krust A, Gansmuller A, Dierich A, Chambon $P$, Mark M. Effect of single and compound knockouts of estrogen receptors alpha (ERalpha) and beta (ERbeta) on mouse reproductive phenotypes. Development. 2000; 127:4277-91.

PMID:10976058

17. Zeng R, Chen Y, Zhao S, Cui GH. Autophagy counteracts apoptosis in human multiple myeloma cells exposed to oridonin in vitro via regulating intracellular ROS and SIRT1. Acta Pharmacol Sin. 2012; 33:91-100.

https://doi.org/10.1038/aps.2011.143 PMID:22158107

18. Wang D, He X, Wang D, Peng P, Xu X, Gao B, Zheng C, Wang H, Jia H, Shang Q, Sun Z, Luo Z, Yang L. Quercetin Suppresses Apoptosis and Attenuates Intervertebral Disc Degeneration via the SIRT1-Autophagy Pathway. Front Cell Dev Biol. 2020; 8:613006. https://doi.org/10.3389/fcell.2020.613006 PMID: $\underline{33363176}$

19. Zhang WX, He BM, Wu Y, Qiao JF, Peng ZY. Melatonin protects against sepsis-induced cardiac dysfunction by regulating apoptosis and autophagy via activation of SIRT1 in mice. Life Sci. 2019; 217:8-15. https://doi.org/10.1016/i.lfs.2018.11.055 PMID:30500551

20. Wang S, Deng Z, Ma Y, Jin J, Qi F, Li S, Liu C, Lyu FJ,
Zheng Q. The Role of Autophagy and Mitophagy in Bone Metabolic Disorders. Int J Biol Sci. 2020; 16:2675-91.

https://doi.org/10.7150/ijbs.46627

PMID:32792864

21. Shen S, Liao Q, Liu J, Pan R, Lee SM, Lin L. Myricanol rescues dexamethasone-induced muscle dysfunction via a sirtuin 1-dependent mechanism. J Cachexia Sarcopenia Muscle. 2019; 10:429-44.

https://doi.org/10.1002/jcsm.12393

PMID:30793539

22. Zainabadi K, Liu CJ, Caldwell AL, Guarente L. SIRT1 is a positive regulator of in vivo bone mass and a therapeutic target for osteoporosis. PLoS One. 2017; 12:e0185236.

https://doi.org/10.1371/journal.pone.0185236 PMID:28937996

23. Wang H, Hu Z, Wu J, Mei Y, Zhang Q, Zhang H, Miao D, Sun W. Sirt1 Promotes Osteogenic Differentiation and Increases Alveolar Bone Mass via Bmi1 Activation in Mice. J Bone Miner Res. 2019; 34:1169-81. https://doi.org/10.1002/ibmr.3677 PMID:30690778

24. Yang $X$, Jiang $T$, Wang $Y$, Guo L. The Role and Mechanism of SIRT1 in Resveratrol-regulated Osteoblast Autophagy in Osteoporosis Rats. Sci Rep. 2019; 9:18424.

https://doi.org/10.1038/s41598-019-44766-3 PMID:31804494

25. Yao H, Yao Z, Zhang S, Zhang W, Zhou W. Upregulation of SIRT1 inhibits H2O2-induced osteoblast apoptosis via FoxO1/ $\beta$-catenin pathway. Mol Med Rep. 2018; 17:6681-90.

https://doi.org/10.3892/mmr.2018.8657 PMID:29512706

26. Yin X, Zhou C, Li J, Liu R, Shi B, Yuan Q, Zou S. Autophagy in bone homeostasis and the onset of osteoporosis. Bone Res. 2019; 7:28.

https://doi.org/10.1038/s41413-019-0058-7 PMID:31666998

27. Wang T, Liu X, He C. Glucocorticoid-induced autophagy and apoptosis in bone. Apoptosis. 2020; 25:157-68. https://doi.org/10.1007/s10495-020-01599-0 PMID:32157482

28. Zhu W, Ding W, Shang X, Zhu D, Dai X. Fangchinoline Promotes Autophagy and Inhibits Apoptosis in Osteoporotic Rats. Med Sci Monit. 2019; 25:324-32. https://doi.org/10.12659/MSM.912624 PMID: $\underline{30632520}$

29. Wang L, Zhang HY, Gao B, Shi J, Huang Q, Han YH, Hu YQ, Lu WG, Zhao ZJ, Liu BH, Jie Q, Yang L, Luo ZJ. Tetramethylpyrazine Protects Against GlucocorticoidInduced Apoptosis by Promoting Autophagy in 
Mesenchymal Stem Cells and Improves Bone Mass in Glucocorticoid-Induced Osteoporosis Rats. Stem Cells Dev. 2017; 26:419-30.

https://doi.org/10.1089/scd.2016.0233

PMID:27917698

30. Gavali S, Gupta MK, Daswani B, Wani MR, Sirdeshmukh $\mathrm{R}$, Khatkhatay MI. Estrogen enhances human osteoblast survival and function via promotion of autophagy. Biochim Biophys Acta Mol Cell Res. 2019; 1866:1498-507.

https://doi.org/10.1016/j.bbamcr.2019.06.014 PMID:31255720

31. Zhang X, Huang F, Chen X, Wu X, Zhu J. Ginsenoside Rg3 attenuates ovariectomy-induced osteoporosis via AMPK/mTOR signaling pathway. Drug Dev Res. 2020; 81:875-84.

https://doi.org/10.1002/ddr.21705 PMID:32898934

32. Kim J, Kundu M, Viollet B, Guan KL. AMPK and mTOR regulate autophagy through direct phosphorylation of Ulk1. Nat Cell Biol. 2011; 13:132-41. https://doi.org/10.1038/ncb2152 PMID:21258367

33. Alcendor RR, Gao S, Zhai P, Zablocki D, Holle E, Yu X, Tian B, Wagner T, Vatner SF, Sadoshima J. Sirt1 regulates aging and resistance to oxidative stress in the heart. Circ Res. 2007; 100:1512-21. https://doi.org/10.1161/01.RES.0000267723.65696.4a PMID:17446436

34. Ferber EC, Peck B, Delpuech O, Bell GP, East P, Schulze A. FOXO3a regulates reactive oxygen metabolism by inhibiting mitochondrial gene expression. Cell Death Differ. 2012; 19:968-79.

https://doi.org/10.1038/cdd.2011.179 PMID:22139133

35. Brunet A, Sweeney LB, Sturgill JF, Chua KF, Greer PL, Lin $\mathrm{Y}$, Tran $\mathrm{H}$, Ross SE, Mostoslavsky R, Cohen HY, Hu LS, Cheng HL, Jedrychowski MP, et al. Stressdependent regulation of FOXO transcription factors by the SIRT1 deacetylase. Science. 2004; 303:2011-15.

https://doi.org/10.1126/science.1094637 PMID:14976264

36. Sun W, Qiao W, Zhou B, Hu Z, Yan Q, Wu J, Wang R, Zhang $Q$, Miao D. Overexpression of Sirt1 in mesenchymal stem cells protects against bone loss in mice by FOXO3a deacetylation and oxidative stress inhibition. Metabolism. 2018; 88:61-71.

https://doi.org/10.1016/j.metabol.2018.06.006 PMID:30318050

37. Harris SA, Enger RJ, Riggs BL, Spelsberg TC. Development and characterization of a conditionally immortalized human fetal osteoblastic cell line. J Bone Miner Res. 1995; 10:178-86. https://doi.org/10.1002/jbmr.5650100203

\section{PMID:7754797}

38. Munafó DB, Colombo MI. A novel assay to study autophagy: regulation of autophagosome vacuole size by amino acid deprivation. J Cell Sci. 2001; 114:3619-29.

PMID:11707514

39. Xue JF, Shi ZM, Zou J, Li XL. Inhibition of $\mathrm{PISK} / \mathrm{AKT} / \mathrm{mTOR}$ signaling pathway promotes autophagy of articular chondrocytes and attenuates inflammatory response in rats with osteoarthritis. Biomed Pharmacother. 2017; 89:1252-61. https://doi.org/10.1016/i.biopha.2017.01.130 PMID:28320092

40. Baur JA. Biochemical effects of SIRT1 activators. Biochim Biophys Acta. 2010; 1804:1626-34. https://doi.org/10.1016/i.bbapap.2009.10.025 PMID:19897059

41. Botta G, De Santis LP, Saladino R. Current advances in the synthesis and antitumoral activity of SIRT1-2 inhibitors by modulation of p53 and pro-apoptotic proteins. Curr Med Chem. 2012; 19:5871-84. https://doi.org/10.2174/092986712804143303 PMID:22998567

42. Eastell R, O'Neill TW, Hofbauer LC, Langdahl B, Reid IR, Gold DT, Cummings SR. Postmenopausal osteoporosis. Nat Rev Dis Primers. 2016; 2:16069.

https://doi.org/10.1038/nrdp.2016.69 PMID:27681935

43. Zuo HL, Xin H, Yan XN, Huang J, Zhang YP, Du H. 17ßEstradiol improves osteoblastic cell function through the Sirt1/NF-KB/MMP-8 pathway. Climacteric. 2020; 23:404-09. https://doi.org/10.1080/13697137.2020.1758057 PMID:32410477

44. Xiao Y, Li B, Liu J. MicroRNA-148a inhibition protects against ovariectomy-induced osteoporosis through PI3K/AKT signaling by estrogen receptor $\alpha$. Mol Med Rep. 2018; 17:7789-96.

https://doi.org/10.3892/mmr.2018.8845 PMID:29620276

45. Vinel A, Coudert AE, Buscato M, Valera MC, Ostertag A, Katzenellenbogen JA, Katzenellenbogen BS, Berdal A, Babajko S, Arnal JF, Fontaine C. Respective role of membrane and nuclear estrogen receptor (ER) $\alpha$ in the mandible of growing mice: Implications for ER $\alpha$ modulation. J Bone Miner Res. 2018; 33:1520-31. https://doi.org/10.1002/ibmr.3434 PMID:29624728

46. Khan M, Ullah R, Rehman SU, Shah SA, Saeed K, Muhammad T, Park HY, Jo MH, Choe K, Rutten BP, Kim MO. 17ß-Estradiol Modulates SIRT1 and Halts Oxidative Stress-Mediated Cognitive Impairment in a Male Aging Mouse Model. Cells. 2019; 8:928. https://doi.org/10.3390/cells8080928 PMID: $\underline{1430865}$ 
47. Xing JJ, Hou JG, Ma ZN, Wang Z, Ren S, Wang YP, Liu WC, Chen C, Li W. Ginsenoside Rb3 provides protective effects against cisplatin-induced nephrotoxicity via regulation of AMPK-/mTOR-mediated autophagy and inhibition of apoptosis in vitro and in vivo. Cell Prolif. 2019; 52:e12627.

https://doi.org/10.1111/cpr.12627 PMID:31094028

48. Zainabadi K. Drugs targeting SIRT1, a new generation of therapeutics for osteoporosis and other bone related disorders? Pharmacol Res. 2019; 143:97-105. https://doi.org/10.1016/i.phrs.2019.03.007 PMID: $\underline{30862606}$

49. Li Q, Cheng JC, Jiang Q, Lee WY. Role of sirtuins in bone biology: Potential implications for novel therapeutic strategies for osteoporosis. Aging Cell. 2021; 20:e13301. https://doi.org/10.1111/acel.13301 PMID:33393735

50. Chen Y, Zhou F, Liu H, Li J, Che H, Shen J, Luo E. SIRT1, a promising regulator of bone homeostasis. Life Sci. 2021; 269:119041.

https://doi.org/10.1016/j.Ifs.2021.119041

PMID:33453243

51. Gu X, Han D, Chen W, Zhang L, Lin Q, Gao J, Fanning S, Han B. SIRT1-mediated FoxOs pathways protect against apoptosis by promoting autophagy in osteoblast-like MC3T3-E1 cells exposed to sodium fluoride. Oncotarget. 2016; 7:65218-30.

https://doi.org/10.18632/oncotarget.11573

PMID:27564107

52. Han L, Wang $P$, Zhao $G$, Wang $H$, Wang $M$, Chen J, Tong T. Upregulation of SIRT1 by $17 \beta$-estradiol depends on ubiquitin-proteasome degradation of PPAR- $\gamma$ mediated by NEDD4-1. Protein Cell. 2013; 4:310-21.

https://doi.org/10.1007/s13238-013-2124-z PMID:23549616

53. Shen T, Ding L, Ruan Y, Qin W, Lin Y, Xi C, Lu Y, Dou L, Zhu $Y$, Cao $Y$, Man $Y$, Bian $Y$, Wang S, et al. SIRT1 functions as an important regulator of estrogenmediated cardiomyocyte protection in angiotensin IIinduced heart hypertrophy. Oxid Med Cell Longev. 2014; 2014:713894.

https://doi.org/10.1155/2014/713894

PMID:25614777

54. Inoki K, Kim J, Guan KL. AMPK and mTOR in cellular energy homeostasis and drug targets. Annu Rev Pharmacol Toxicol. 2012; 52:381-400.

https://doi.org/10.1146/annurev-pharmtox-010611134537 PMID:22017684

55. Feng X, Pan J, Li J, Zeng C, Qi W, Shao Y, Liu X, Liu L, Xiao G, Zhang H, Bai X, Cai D. Metformin attenuates cartilage degeneration in an experimental osteoarthritis model by regulating AMPK/mTOR. Aging
(Albany NY). 2020; 12:1087-103. https://doi.org/10.18632/aging.102635 PMID:31945013

56. Lin M, Hua R, Ma J, Zhou Y, Li P, Xu X, Yu Z, Quan S. Bisphenol A promotes autophagy in ovarian granulosa cells by inducing AMPK/mTOR/ULK1 signalling pathway. Environ Int. 2021; 147:106298. https://doi.org/10.1016/j.envint.2020.106298 PMID:33387880

57. Chotiyarnwong P, McCloskey EV. Pathogenesis of glucocorticoid-induced osteoporosis and options for treatment. Nat Rev Endocrinol. 2020; 16:437-47.

https://doi.org/10.1038/s41574-020-0341-0

PMID:32286516

58. Al Saedi A, Goodman CA, Myers DE, Hayes A, Duque G. Rapamycin Affects Palmitate-Induced Lipotoxicity in Osteoblasts by Modulating Apoptosis and Autophagy. J Gerontol A Biol Sci Med Sci. 2020; 75:58-63. https://doi.org/10.1093/gerona/glz149 PMID: $\underline{31241126}$

59. Deng Z, Wang Z, Jin J, Wang Y, Bao N, Gao Q, Zhao J. SIRT1 protects osteoblasts against particle-induced inflammatory responses and apoptosis in aseptic prosthesis loosening. Acta Biomater. 2017; 49:541-54. https://doi.org/10.1016/i.actbio.2016.11.051 PMID:27890623

60. Calvanese V, Fraga MF. SirT1 brings stemness closer to cancer and aging. Aging (Albany NY). 2011; 3:162-67.

https://doi.org/10.18632/aging.100272 PMID:21307403

61. Huang $X$, Shi $Y$, Chen $H$, Le R, Gong X, Xu K, Zhu Q, Shen F, Chen Z, Gu X, Chen X, Chen X. Isoliquiritigenin prevents hyperglycemia-induced renal injuries by inhibiting inflammation and oxidative stress via SIRT1dependent mechanism. Cell Death Dis. 2020; 11:1040.

https://doi.org/10.1038/s41419-020-03260-9

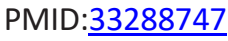

62. Ambrogini $E$, Almeida $M$, Martin-Millan $M$, Paik JH, Depinho RA, Han L, Goellner J, Weinstein RS, Jilka RL, O'Brien CA, Manolagas SC. FoxO-mediated defense against oxidative stress in osteoblasts is indispensable for skeletal homeostasis in mice. Cell Metab. 2010; 11:136-46.

https://doi.org/10.1016/i.cmet.2009.12.009 PMID:20142101

63. Almeida M. Unraveling the role of FoxOs in boneinsights from mouse models. Bone. 2011; 49:319-27. https://doi.org/10.1016/j.bone.2011.05.023 PMID:21664311

64. Tang KC, Pan W, Doschak MR, Alexander RT. Increased 
FoxO3a expression prevents osteoblast differentiation and matrix calcification. Bone Rep. 2019; 10:100206. https://doi.org/10.1016/i.bonr.2019.100206 PMID:31193232

65. Kuroyanagi G, Otsuka T, Yamamoto N, MatsushimaNishiwaki R, Nakakami A, Mizutani J, Kozawa O, Tokuda H. Down-regulation by resveratrol of basic fibroblast growth factor-stimulated osteoprotegerin synthesis through suppression of Akt in osteoblasts. Int J Mol Sci. 2014; 15:17886-900.

https://doi.org/10.3390/ijms151017886

PMID:25290095

66. Kuroyanagi G, Mizutani J, Kondo A, Yamamoto N, Matsushima-Nishiwaki R, Otsuka T, Kozawa O, Tokuda $\mathrm{H}$. Suppression by resveratrol of prostaglandin D2stimulated osteoprotegerin synthesis in osteoblasts. Prostaglandins Leukot Essent Fatty Acids. 2014; 91:73-80.

https://doi.org/10.1016/j.plefa.2014.04.003

PMID:24813642

67. Hong W, Wei Z, Qiu Z, Li Z, Fu C, Ye Z, Xu X. Atorvastatin promotes bone formation in aged apoE $\mathrm{E}^{-/}$ mice through the Sirt1-Runx2 axis. J Orthop Surg Res. 2020; 15:303.

https://doi.org/10.1186/s13018-020-01841-0 PMID:32762716

68. Qu L, Yu Y, Qiu L, Yang D, Yan L, Guo J, Jahan R. Sirtuin 1 regulates matrix metalloproteinase- 13 expression induced by Porphyromonas endodontalis lipopolysaccharide via targeting nuclear factor-кB in osteoblasts. J Oral Microbiol. 2017; 9:1317578.

https://doi.org/10.1080/20002297.2017.1317578 PMID:28473882

69. Kang C, Wei L, Song B, Chen L, Liu J, Deng B, Pan X, Shao L. Involvement of autophagy in tantalum nanoparticle-induced osteoblast proliferation. Int J Nanomedicine. 2017; 12:4323-33.

https://doi.org/10.2147/IJN.S136281

PMID:28652735

70. Zhang C, Lin J, Ge J, Wang LL, Li N, Sun XT, Cao HB, Li JL. Selenium triggers Nrf2-mediated protection against cadmium-induced chicken hepatocyte autophagy and apoptosis. Toxicol In Vitro. 2017; 44:349-56.

https://doi.org/10.1016/j.tiv.2017.07.027 PMID:28765097

71. Zhang L, Wei J, Ren L, Zhang J, Wang J, Jing L, Yang M, Yu Y, Sun Z, Zhou X. Endosulfan induces autophagy and endothelial dysfunction via the AMPK/mTOR signaling pathway triggered by oxidative stress. Environ Pollut. 2017; 220:843-52. https://doi.org/10.1016/i.envpol.2016.10.067 PMID:27814983
72. Zhang L, Wei J, Ren L, Zhang J, Yang M, Jing L, Wang J, Sun Z, Zhou X. Endosulfan inducing apoptosis and necroptosis through activation RIPK signaling pathway in human umbilical vascular endothelial cells. Environ Sci Pollut Res Int. 2017; 24:215-25.

https://doi.org/10.1007/s11356-016-7652-7 PMID:27709431

73. Zheng $Y$, Ma L, Liu N, Tang X, Guo S, Zhang B, Jiang Z. Autophagy and Apoptosis of Porcine Ovarian Granulosa Cells During Follicular Development. Animals (Basel). 2019; 9:1111. https://doi.org/10.3390/ani9121111 PMID:31835576

74. Guo Q, Wang B, Wang X, Smith WW, Zhu Y, Liu Z. Activation of Nrf2 in Astrocytes Suppressed PD-Like Phenotypes via Antioxidant and Autophagy Pathways in Rat and Drosophila Models. Cells. 2021; 10:1850.

https://doi.org/10.3390/cells10081850 PMID:34440619

75. Singh B, Bhaskar S. Methods for Detection of Autophagy in Mammalian Cells. Methods Mol Biol. 2019; 2045:245-58. https://doi.org/10.1007/7651_2018 190 PMID: $\underline{0242567}$

76. Zhu Y, Chen G, Chen L, Zhang W, Feng D, Liu L, Chen Q. Monitoring mitophagy in mammalian cells. Methods Enzymol. 2014; 547:39-55. https://doi.org/10.1016/B978-0-12-801415-8.00003-5 PMID:25416351

77. Chen L, Shi X, Weng SJ, Xie J, Tang JH, Yan DY, Wang BZ, Xie ZJ, Wu ZY, Yang L. Vitamin K2 Can Rescue the Dexamethasone-Induced Downregulation of Osteoblast Autophagy and Mitophagy Thereby Restoring Osteoblast Function In Vitro and In Vivo. Front Pharmacol. 2020; 11:1209. https://doi.org/10.3389/fphar.2020.01209 PMID: $\underline{32848799}$

78. Lv C, Wang L, Zhu X, Lin W, Chen X, Huang Z, Huang L, Yang S. Glucosamine promotes osteoblast proliferation by modulating autophagy via the mammalian target of rapamycin pathway. Biomed Pharmacother. 2018; 99:271-77.

https://doi.org/10.1016/i.biopha.2018.01.066 PMID:29334671

79. Mei R, Lou P, You G, Jiang T, Yu X, Guo L. 17ß-Estradiol Induces Mitophagy Upregulation to Protect Chondrocytes via the SIRT1-Mediated AMPK/mTOR Signaling Pathway. Front Endocrinol (Lausanne). 2021; 11:615250.

https://doi.org/10.3389/fendo.2020.615250 PMID: $\underline{3613450}$

80. Mai $H$, Wei $Y$, Yin $Y$, Huang $S$, Lin $H$, Liao $Y$, Liu $X$, Chen $X$, Shi H, Liu C, Xu H. LINC01541 overexpression 
attenuates the $17 \beta$-Estradiol-induced migration and invasion capabilities of endometrial stromal cells. Syst Biol Reprod Med. 2019; 65:214-22.

https://doi.org/10.1080/19396368.2018.1549290

PMID:30608887

81. Ketcherside A, Noble $\amalg$, Mclntyre CK, Filbey FM. Cannabinoid Receptor 1 Gene by Cannabis Use Interaction on CB1 Receptor Density. Cannabis Cannabinoid Res. 2017; 2:202-09.

https://doi.org/10.1089/can.2017.0007

PMID:29082317

82. White WL. Erratum to: Why I hate the index finger. Hand (N Y). 2011; 6:233.

https://doi.org/10.1007/s11552-011-9321-0

PMID:21776199
83. Shen T, Yang C, Ding L, Zhu Y, Ruan Y, Cheng H, Qin W, Huang $X$, Zhang $H$, Man $Y$, Liu D, Wang $S$, Bian $Y$, et al. Tbx20 functions as an important regulator of estrogenmediated cardiomyocyte protection during oxidative stress. Int J Cardiol. 2013; 168:3704-14.

https://doi.org/10.1016/j.ijcard.2013.06.018 PMID:23871353 


\section{SUPPLEMENTARY MATERIALS}

\section{Supplementary Figure}

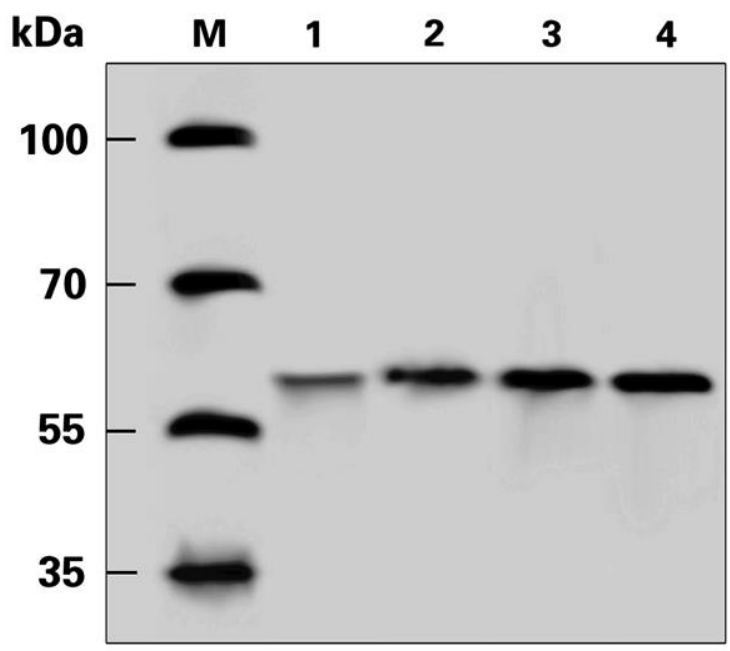

Supplementary Figure 1. The original gel acquisition of the Western blot shown in Figure 1A. M: marker protein, 1: control group

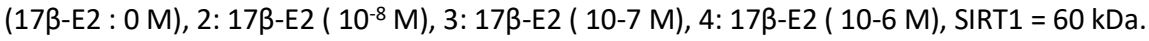

